\title{
Estudios
}

JOSÉ LUIS SÁNCHEZ-GIRÓN RENEDO, SJ *

\section{EL «MOTU PROPRIO» «VOS ESTIS LUX MUNDI»: CONTENIDOS Y RELACIÓN CON OTRAS NORMAS DEL DERECHO CANÓNICO VIGENTE}

Fecha de recepción: 30 de septiembre de 2019

Fecha de aceptación y versión final: 22 de octubre de 2019

RESUMEN: El m. p. Vos estis lux mundi (mayo de 2019) prescribe obligaciones canónicas relacionadas con informar a las autoridades de la Iglesia sobre abusos sexuales de menores y personas vulnerables, y conductas relacionadas con la pornografía infantil, que sean llevadas a cabo por clérigos (incluidos cardenales, obispos y legados) y religiosos/as; y también sobre acciones de gobierno en la Iglesia que eludan o interfieran la investigación de esos hechos. Sobre la respuesta final que se dé a los mismos, se remite más bien a lo que ya esté dispuesto en el derecho de Iglesia para cada caso, pero solo la obligatoriedad acerca de la información es ya un paso importante. El texto podría requerir alguna clarificación acerca del tratamiento que haya de darse a algunos de los hechos y conductas que recoge, y habrá de ponerse en relación con la legislación estatal en materia de obligaciones de informar.

PALABRAS CLAVE: delito; delito reservado; informe; menor; pena; secreto; vulnerable.

Facultad de Derecho Canónico, Universidad Pontificia Comillas: jlsgiron@comillas.edu; ORCID: https://orcid.org/0000-0002-6798-6324 


\section{The "motu proprio" "Vos Estis Lux Mundi»: Contents and Relationship with other Norms of the Current Canon Law}

ABSTRACT: The m. p. Vos estis lux mundi (May 2019) prescribes canonical obligations related to informing Church authorities about sexual abuse of minors and vulnerable people, as well as behaviors related to child pornography, which are carried out by clergy (including Cardinals, Bishops and Legacies) and religious; and also about government actions in the Church that elude or interfere with the investigation of these facts. In regard to the final answer given to them, it refers rather to what is already available in the law of the Church for each case, but just the obligatory nature of the information is already an important step. The text may require some clarification about the treatment that should receive some of the facts and behaviors that it collects, and we will have to establish a relationship with state legislation regarding information obligations.

KEY WORDS: delict; reserved delict; report; minor; penalti; secret; vulnerable.

El pasado 7 de mayo de 2019 el papa Francisco aprobaba el m. p. Vos estis lux mundi (VELM), disponiendo al final del texto que la promulgación se haga a través del diario de la Santa Sede l'Osservatore Romano y que su entrada en vigor para toda la Iglesia fuera el 1 de junio de ese mismo año. En el acceso informático a la edición del 9 de mayo de este periódico se aprecia que el texto fue publicado en italiano ${ }^{1}$, versión a la que, asimismo, se accede a través de la página web oficial de la Santa Sede en la cual aparece también en otras lengua modernas; entre ellas el español (no hay texto en latín), versión de la que se hará uso en esta contribución ${ }^{2}$.

El m. p. (19 artículos en dos títulos) se refiere a determinadas conductas de índole sexual y, según a quién se atribuyan, establece en dos títulos cómo se ha de proceder en cada caso. La introducción hace ver que estos hechos «causan daños físicos, psicológicos y espirituales a las víctimas, y perjudican a la comunidad de los fieles», planteando que para superar esta problemática se precisa «una continua y profunda conversión

${ }^{1}$ Cf. "Nuevas normas para toda la Iglesia contra quien abusa o encubre", Andrea Tornielli, visitado en septiembre de 2019, http://www.osservatoreromano.va/es/news/ nuevas-normas-para-toda-la-iglesia-contra-quien-ab

2 "Carta Apostólica en forma motu proprio del Sumo Pontífice Francisco Vos estis lux mundi”, Santa Sede, visitado en septiembre de 2019, http://w2.vatican.va/content/ francesco/es/motu_proprio/documents/papa-francesco-motu-proprio-20190507_vosestis-lux-mundi.html 
de los corazones, acompañada de acciones concretas y eficaces que involucren a todos en la Iglesia». No obstante, señala más en particular a los obispos y a quienes «en diversos modos, realizan ministerios en la Iglesia, profesan los consejos evangélicos o están llamados a servir al pueblo cristiano».

El documento ha de ponerse en la línea de las iniciativas que la Santa Sede va adoptando para combatir estas conductas, y está especialmente relacionado con el encuentro que hubo en el Vaticano en febrero de 2019 en torno a los casos de abuso sexual a menores de edad por miembros del clero que desde hace años afectan tan gravemente a la Iglesia ${ }^{3}$. En este tiempo, tanto en el nivel universal como en niveles locales de la Iglesia, no han faltado normas vinculantes referidas a estos casos ni documentos de carácter orientador sobre cómo proceder a modo de «guías de actuación» ${ }^{4}$. También estos últimos han podido contribuir a generar medidas y actuaciones eficaces para los objetivos que se buscan, pero no siendo estrictamente normas de obligado cumplimiento les falta esa capacidad de asegurar que se lleve a cabo lo que en ellos se contiene ${ }^{5}$.

VELM, cuyo ámbito de aplicación es toda la Iglesia (la introducción anticipa que se van a establecer procedimientos «a nivel universal»), ha de ponerse en cambio en la línea de los textos normativos que se deben cumplir, y a partir de aquí cobra mayor sentido estudiar su encaje con otros

${ }^{3}$ Cf. Andrea Tornielli, "Nuevas normas para toda la Iglesia contra quien abusa o encubre". También, cf., "El Papa acepta pasar de la retórica a 'medidas concretas y eficaces"', Daniel Verdú, visitado en septiembre de 2019, https://elpais.com/sociedad/2019/02/21/actualidad/1550734755_267380.html

${ }^{4}$ Para una aproximación a un tipo y otro de textos, cf. Rafael Felipe Freije, "Respuesta eclesial y canónica a los abusos sexuales de menores bajo el impulso de J. Ratzinger, Prefecto y Papa" (Tesis doctoral en Derecho Canónico, U. P. Comillas-Madrid, 2019), 45-74. Sobre los del segundo tipo, cf., también, John Paul Kimes, “Simul et cura et solertia. Guidelines of the Episcopal Conferences for dealing with cases of sexual abuses of minors perpetrated by clerics", en I delitti riservati alla Congregazione per la Dottrina della Fede. Norme, prassi, obbiezioni, dir. Claudio Papale (Città del Vaticano: Urbaniana University Press, 2015), 25-44.

5 Cf. Felipe, "Respuesta eclesial y canónica", 73, citando a Hans Zollner, SJ, Director del centro para la Protección del Menor de la Pontificia Università Gregoriana, cf. "Pedofilia/Vaticano: Experto en defensa de los menores responde a las acusaciones de la ONU”, Alessia Giuliani, visitado en septiembre de 2019, https:// es.aleteia.org/2014/02/15/pedofiliavaticano-experto-en-defensa-de-los-menores-responde-a-las-acusaciones-de-la-onu/ 
documentos vigentes de esa misma naturaleza ${ }^{6}$. La presente contribución se centrará en este enfoque, sin ánimo exhaustivo sino de seleccionar algunas cuestiones que bajo este punto de vista se consideran relevantes.

\section{HECHOS Y AUTORES}

Los hechos a los que se refiere VELM están recogidos en el art. 1 con el siguiente tenor literal:

Art. 1. Ámbito de aplicación

$\S 1$. Las presentes normas se aplican en el caso de informes relativos a clérigos o miembros de Institutos de vida consagrada o Sociedades de vida apostólica con relación a:

a) delitos contra el sexto mandamiento del Decálogo que consistan en:

I. obligar a alguien, con violencia o amenaza o mediante abuso de autoridad, a realizar o sufrir actos sexuales;

II. realizar actos sexuales con un menor o con una persona vulnerable;

III. producir, exhibir, poseer o distribuir, incluso por vía telemática, material pornográfico infantil, así como recluir o inducir a un menor o a una persona vulnerable a participar en exhibiciones pornográficas;

b) conductas llevadas a cabo por los sujetos a los que se refiere el artículo 6, que consisten en acciones u omisiones dirigidas a interferir o eludir investigaciones civiles o investigaciones canónicas, administrativas o penales, contra un clérigo o un religioso con respecto a delitos señalados en la letra a) de este parágrafo.

$\S 2$. A los efectos de las presentes normas, se entiende por:

a) «menor»: cualquier persona con una edad inferior a dieciocho años o legalmente equiparada a ella;

b) «persona vulnerable»: cualquier persona en estado de enfermedad, de deficiencia física o psicológica, o de privación de la libertad personal que, de hecho, limite incluso ocasionalmente

${ }^{6}$ Mons. Juan Ignacio Arrieta, Secretario del Pontificio Consejo para los Textos Legislativos, puntualiza esta distinción y afirma el carácter vinculante de VELM, cf. “Monseñor Arrieta: el motu proprio 'Vos estis lux mundi' es 'un paso de la Iglesia para la claridad y la transparencia”, Rosa Die Alcolea, visitado en septiembre de 2019, https://www.revistaecclesia.com/monsenor-arrieta-el-motu-proprio-vos-estis-lux-mundi-es-un-paso-de-la-iglesia-para-la-claridad-y-la-transparencia/ 
su capacidad de entender o de querer o, en cualquier caso, de resistir a la ofensa;

c) «material pornográfico infantil»: cualquier representación de un menor, independientemente de los medios utilizados, involucrado en actividades sexuales explícitas, reales o simuladas, y cualquier representación de órganos sexuales de menores con fines predominantemente sexuales.

Digamos ya que los «sujetos» contemplados en el art. 6, a los que se refiere el art. $1 \S 1 \mathrm{~b}$, son los siguientes:

a) cardenales, patriarcas, obispos y legados del romano pontífice;

b) clérigos que están o que han estado encargados del gobierno pastoral de una Iglesia particular o de una entidad a ella asimilada, latina u oriental, incluidos los ordinariatos personales, por los hechos cometidos durante munere;

c) clérigos que están o que han estado encargados del gobierno pastoral de una Prelatura personal, por los hechos cometidos durante munere;

d) aquellos que son o que han sido moderadores supremos de Institutos de vida consagrada o de Sociedades de vida apostólica de derecho pontificio, así como de los monasterios sui iuris, por los hechos cometidos durante munere.

La mención a los Patriarcas y la Iglesia particular oriental refleja el ámbito universal de aplicación de VELM al que se ha hecho referencia, que abarca también a las Iglesias católico-orientales; como, asimismo, se refleja en las menciones explícitas al CCEO (de 1990), que es la regulación fundamental de las mismas como en la Iglesia latina lo es el vigente CIC de 1983. Pese al enorme valor e interés que tienen las Iglesias católicas de rito oriental, este trabajo prescindirá de las mismas y de las peculiaridades de su legislación, centrándose únicamente en el ámbito de la Iglesia católica de rito latino. En cuanto a los cardenales, obispos y legados del papa (cc. 362-367) no se ve especial necesidad de hacer más aclaraciones aquín.

En cuanto a la letra b) hay que señalar que la «Iglesia particular» es principalmente la diócesis, cuyo gobierno pastoral se encomienda a un

${ }^{7}$ Los legados pontificios (cc. 362-367) son nombrados por el papa para que en una nación le representen ante las Iglesias particulares que haya en ella o también ante el Estado. El tipo de legado más conocido (que ostenta ambas representaciones) es el nuncio. 
obispo diocesano, y que se consideran asimiladas a ella otras «entidades» recogidas en el c. 368 al frente de las cuales puede haber, según los casos, un obispo o un sacerdote que, en cualquiera de los supuestos, se equipara en derecho al obispo diocesano (c. $381 \S 2)^{8}$. Como se ve, el texto hace referencia al "clérigo", lo cual incluye a los diáconos (c. 266) y a los sacerdotes (o "presbíteros») $)^{9}$. En cuanto al «ordinariato personal», esto se refiere (c. 372) a que la determinación de los fieles de una diócesis sigue por lo general un criterio territorial (de manera que pertenecen a ella los que habiten en el territorio que se determine), pero se puede seguir también un criterio personal de modo que pertenecen a la diócesis quienes, por ejemplo, son de un determinado rito (c. 372 \$2 ${ }^{10}$. En la letra c) cabe entender que el texto se hace eco de que en una prelatura personal (cc. 294-297) no es estrictamente necesario que quien esté encargado de su gobierno pastoral sea obispo ${ }^{11}$.

La letra d) se refiere a los Institutos de vida consagrada (IVC) y a las Sociedades de vida apostólica (SVA). El CIC regula unas y otros en la Parte III del Libro II, donde vemos que los IVC son los Institutos Religiosos (IR) y los Institutos Seculares (cc. 607-709 y 710-730, respectivamente) y que las SVA (cc. 731-746) «se asemejan» a ellos (c. 731). En buena medida la regulación de los Institutos Seculares y las SVA se hace por remisión a la de los IR, por lo cual este trabajo, para simplificar, se

8 Estas «entidades» son la abadía y la prelatura territoriales, así como el vicariato, la prefectura y la administración apostólicas. Lo habitual es que el gobierno de la prelatura y el vicariato se encomiende a un obispo, y en los demás casos a un sacerdote, cf. Gianfranco Ghirlanda, El derecho en la Iglesia misterio de comunión. Compendio de derecho eclesial (Madrid: Ediciones Paulinas, 1992) 637-638.

9 Cf. Tomás Rincón Pérez, "Titulus III. De ministris sacris seu clericis. Introducción", en Comentario exegético al Código de Derecho Canónico, 3. a ed., dir. A. Marzoa, J. Miras, y R. Rodríguez-Ocaña (Barañáin-Navarra: EUNSA, 2002), 1:207. Cabría entender que el texto integra también el supuesto del sacerdote que rija provisionalmente una diócesis cuando cesa su obispo y aún no ha tomado posesión el que le sucederá (sede vacante). En esta situación el CIC prevé un procedimiento (cc. 416-430) por el cual es posible que un sacerdote rija en este tiempo la diócesis como «administrador diocesano", aunque no con las mismas facultades que un obispo diocesano.

${ }^{10}$ Un caso muy habitual de diócesis personal es el Ordinariato militar constituido en numerosos países, al que pertenecen los miembros de su ejército, cf. Ghirlanda, 638-639.

${ }^{11}$ Cf. Juan Ignacio Arrieta, "Prelatura personal", en Diccionario General de Derecho Canónico, dir. Javier Otaduy, Antonio Viana, y Joaquín Sedano (Cizur Menor, Navarra: Universidad de Navarra-Thomson Reuters Aranzadi, 2012), 6:395. 
referirá en adelante solo a ellos. El moderador supremo (c. 592 §1) se denomina también superior general ${ }^{12}$, y es el miembro del Instituto que tiene autoridad sobre todos los que pertenecen al mismo. El texto limita los efectos de las disposiciones de VELM que se refieran a esta letra solo a los superiores generales de los IR de derecho pontificio, dejando fuera a los de derecho diocesano ${ }^{13}$; pero, no haciendo más matices, está incluyendo tanto a los IR de derecho pontificio clericales como a los laicales ${ }^{14}$. Por tanto, entre los laicales incluye tanto a los masculinos como a los femeninos, de modo que abarca tanto a superiores como a superioras generales ${ }^{15}$. En cuanto a los monasterios sui iuris, el término hace referencia, en la vida monástica, a una comunidad monacal que vive su específica vocación religiosa de manera autónoma, como persona jurídica independiente que tiene su propio superior elegido legítimamente, pudiendo agruparse varios monasterios formando federaciones (de aquí surgen las congregaciones monásticas $)^{16}$.

Vemos, pues, que VELM se refiere a las conductas recogidas en el art. $1 \S 1 \mathrm{~b}$ de interferir o eludir investigaciones sobre hechos contemplados en el art. $1 \S 1$ a solo en tanto hayan sido llevadas a cabo por quienes

12 Cf. Jorge Horta, "Superior General”, en Diccionario General..., 6:457-458.

13 Los de derecho pontificio han recibido una aprobación formal de la Santa Sede y los de derecho diocesano no (c. 589).

${ }^{14}$ Se distinguen en que la dirección de los IR clericales se encomienda a miembros que son clérigos (c. 588). Para más información sobre estos tipos de IR, cf. William. H. Woestman, "Instituto clerical" en Diccionario General..., 6:636-638; Benoît Malvaux, "Instituto de derecho diocesano", en ibid., 639-641; Stephan Haering, "Instituto de derecho pontificio", en ibid., 641-644. En todo caso, en los IR clericales hay miembros que no son clérigos (ni sacerdotes ni diáconos) bien porque se están preparando para serlo cuando sean ordenados (recibiendo el sacramento del orden) o bien porque no se ordenan (en algunos se les llama "hermanos"), y hay IR laicales masculinos en los que puede haber algunos clérigos.

15 Por dar algunos datos que puede resultar familiares sobre distintos tipos de IR, digamos que son clericales de derecho pontificio, por ejemplo, los claretianos, dominicos, jesuitas, salesianos, legionarios de Cristo y tantos más. Entre los numerosos IR laicales masculinos de derecho pontificio están, por ejemplo, los Hermanos maristas, los Hermanos de La Salle y los Hermanos de San Juan de Dios; y entre los femeninos están, por ejemplo, las Esclavas del Sagrado Corazón, las Hermanas de la Cruz y las Religiosas de María Inmaculada (las muy conocidas "Hijas de la Caridad" son en cambio una SVA).

16 Cf. Geza Kuminetz, "Monasterio", en Diccionario General..., 5:459. También por simplificar en este trabajo no haremos más mención especial a los monasterios sui iuris sino solo a los IR. 
menciona el art. 6, y no por alguna otra persona. Aún quedaría por matizar que, en el caso de los mencionados en las letras b), c) y d) de este artículo, solo son objeto de las disposiciones del m. p. las conductas del art. $1 \S 1$ b que llevaran a cabo durante munere; es decir, teniendo el cargo de gobernar pastoralmente una Iglesia particular o una entidad asimilada o una prelatura personal, o de moderador supremo de un IR. El m. p. se aplicaría a ellas incluso después de cesar en el cargo, pero no a ese mismo tipo de conductas que en alguna medida pudieran haber tenido antes o después de ejercerlo. Cabe entender que estarían fuera del m. p. las de otros cargos de autoridad durante el ejercicio del mismo, como pueden ser el vicario general de una diócesis u otros superiores que hay en los IR por debajo del moderador supremo ${ }^{17}$. Salvo mejor interpretación, se diría que, en el caso, por ejemplo, de quien es ahora superior general de un IR y antes fue superior provincial, a las conductas del art. $1 \S 1$ b que tuviera ejerciendo ese cargo no le serían aplicables las disposiciones del m. p. por el hecho de que en este momento sea moderador supremo. Como se ve, todas estas matizaciones no se hacen con respecto a los cardenales, obispos y legados ${ }^{18}$.

Supuesto lo anterior acerca de las conductas del art. $1 \S 1 \mathrm{~b}$, en cuanto a los hechos del art. $1 \S 1$ a el propio inicio del $\S 1$ hace ver —anticipando que VELM se va a referir a la información sobre unas y otros- que el m. p. no pretende extender sus efectos a los que realice cualquier persona sino solo a los realizados por clérigos o miembros de IVC o SVA pues, como se vio más arriba, dice que «Las presentes normas se aplican en el caso de informes relativos a clérigos o miembros de Institutos de Vida Consagrada o Sociedades de Vida Apostólica con relación a [...]», y continúa con el texto ya transcrito aquí de las letras a y b en el cual se reflejan los hechos y conductas allí recogidos.

Por tanto, para las conductas del $\S 1 \mathrm{~b}$ el m. p. limita sus efectos a las llevadas a cabo por quienes aparecen mencionados en el art. 6 -donde en el caso de los moderadores supremos se limitan más aún y solo se

17 En los IR hay superiores provinciales y superiores locales. Estos últimos están al frente de una comunidad en la que vive y a la que pertenece un determinado número de religiosos (c. 608). Las Provincias de un IR agrupan comunidades y al frente de cada una hay un superior provincial (cc. 620-622).

${ }_{18}$ Quizá no quede del todo claro si, por ejemplo, se incluyen o no en las disposiciones de VELM las conductas del art. 1 §1b realizadas por un cardenal o un obispo antes de serlo. 
refieren a los de IR de derecho pontificio (retomando el planteamiento ya expresado de que, por simplificar, hablaremos solo a esta modalidad de IVC) - pero vemos que el inicio del art. 1 \$1 no hace este matiz, de modo que no se da para los hechos del art. 1 §1a. Según esto, los efectos del m. p. alcanzan a esos hechos cuando son realizados por cualquier clérigo (sea del clero diocesano o de un IR) y por cualquier miembro que no sea clérigo de un IR de derecho pontificio o de derecho diocesano, sean IR clericales o sean laicales; estos últimos, tanto masculinos como femeninos, de modo que entre los religiosos que no son clérigos el m. p. extiende sus efectos a los hechos del mencionado $\S 1$ a tanto si los hacen varones como si los hacen religiosas. Lógicamente, estos efectos también alcanzan a esos hechos cuando son realizados por quienes aparecen en el art. 6 -únicos a los que afectan las disposiciones relativas a las conductas del art. $1 \S 1 \mathrm{~b}-$ pues todos ellos son clérigos o, en el caso de los moderadores supremos de IR de derecho pontificio que no lo sean, son religiosos o religiosas ${ }^{19}$. Queda claro, pues, que VELM no se refiere en modo alguno a ningún hecho ni conducta que haya realizado o tenido una persona seglar (es decir, que no es clérigo ni religioso/a).

\section{LA OBLIGACIÓN DE INFORMAR: TÍTULO I}

Una vez perfilados los hechos y conductas a los que se refiere VELM (y, en consecuencia, a cuáles no), recogidos en las letras a y b del art. 1 $\S 1$ (con algunas aclaraciones de conceptos a efectos del m. p. en el art. 1 §2) y determinados por la combinación de un elemento objetivo (en qué consisten) y otro subjetivo (personas que los lleven a cabo), se ve que las demás disposiciones del Título I (art. 2-5) se centran en establecer la obligación de informar acerca de unos y otras.

19 Los obispos son clérigos (cf. Rincón Pérez, 207), y los cardenales también ya que por lo general tienen la dignidad episcopal, cf. Carlo Cardia, "Cardenal", en Diccionario General..., 1:852. Lo mismo cabe decir de los legados del papa, cf. Giovanni Battista Varnier, "Legado Pontificio", ibid., 1:1002. Se entiende (ver la nota 14) que el moderador supremo de un IR laical (sea o no de derecho pontificio) es un religioso/a que no es clérigo. 


\subsection{Presentación de informes}

El art. $2 \S 1$ dispone que, en el plazo de un año a partir de la entrada en vigor del m. p. (es decir, hasta el 1 de junio de 2020) «las diócesis [...] individual o conjuntamente, deben establecer [...] uno o más sistemas estables y fácilmente accesibles al público para presentar los informes, incluyendo eventualmente a través de la creación de un oficio eclesiástico específico». Cotejando esto con el pasaje inicial del art. 1 $\S 1$ apenas transcrito resultaría claro que se refiere a informes sobre los hechos y conductas recogidos en las letras a y b del mismo. La obligación se completa con la de informar al legado pontificio acerca de su cumplimiento y la de tomar en consideración las indicaciones que en su caso haya dado la Conferencia Episcopal en torno a esta cuestión.

Con esta disposición VELM se integra en la línea de algunas iniciativas que se van tomando en la Iglesia de cara a facilitar oportunidades de dar a conocer casos de abuso sexual a menores de edad por miembros del clero; un supuesto que sin duda está entre aquellos a los que afecta el m. p. si bien no es el único al que se refiere. En la línea de organismos constituidos con anterioridad cabe hacer mención del Office for child and youth protection, constituido en EE. UU. a raíz de la normativa especial aprobada en 2002 para ese país ${ }^{20}$, que engloba esa función en el marco de otras que abordan distintas dimensiones de esta problemática como la prevención y la atención a las víctimas ${ }^{21}$. Por su parte, la Comisión Pontificia para la Protección de Menores (constituida por el papa Francisco en 2014) ha dado en todos estos aspectos indicaciones de cara al establecimiento de «líneas guía» de actuación por parte de las Conferencias Episcopales, punto al cual vemos que hace referencia el art. $2 \S 1^{22}$. Ya en 2011 la Congregación para la Doctrina de la Fe (CDF) remitió una circular a las Conferencias Episcopales con esta misma finalidad ${ }^{23}$, y en torno a esta ini-

${ }^{20}$ Cf. Felipe, 45.

${ }^{21}$ Cf. "Promise to protect, pledged to heal", Archidiocese of Philadelphia, visitado en septiembre de 2019, https://childyouthprotection.org/.

${ }_{22}$ Cf. "Modelo de líneas guía", Comisión Pontificia para la Protección de Menores, visitado en septiembre de 2019, http://www.protectionofminors.va/content/tuteladeiminori/es/sezionele_risorse/pagina-modello_per_linee_guida.html

${ }_{23}$ Cf. "Subsidio para las Conferencias Episcopales en la preparación de Líneas Guía para tratar los casos de abuso sexual de menores por parte del clero", Congregación para la Doctrina de la Fe, visitado en septiembre de 2019, http:/www.vatican.va/roman_curia/ congregations/cfaith/documents/rc_con_cfaith_doc_20110503_abuso-minori_sp.html 
ciativa ha habido documentos de esta naturaleza emanados por las mismas ${ }^{24}$; por ejemplo, en el caso de España el llamado "Protocolo canónico" y el "Protocolo Civil" referidos a los mencionados casos de abuso sexual ${ }^{25}$.

Con eso y con todo, el paso que se da en VELM es, como ya se ha señalado, el de establecer un verdadera obligación jurídica para los obispos diocesanos (no una indicación de lo que se podría o se anima a hacer), cuyo cumplimiento se prevé que sea revisado (cabe entender que es esta la finalidad de la información que según el propio art. 2 §1 se ha de dar al legado pontificio) y consistente en proporcionar medios que faciliten a cualquiera («al público») el modo de hacer llegar la información que tenga sobre los hechos y conductas a las que se refiere el m. p. (personas de referencia, direcciones postales o electrónicas, adecuada difusión de esta información, etc.) pudiendo llegar para ello a la constitución de una «oficina» (equipo, organismo, comisión, o como se le denomine) ${ }^{26}$. Hay que hacerse cargo de que aportar esta información, especialmente si se ha sido objeto de un abuso sexual por un miembro del clero, no es un paso sencillo, y son importantes una serie de elementos que lo faciliten, como dar una información clara y fácilmente accesible sobre dónde o a quién dirigirse, generar en ella confianza de poder departir con un laico, asignar una persona de apoyo y seguimiento o crear un clima de acogida adecuado ${ }^{27}$.

El m. p. completa sus aportaciones en la línea de lo que estamos diciendo al disponer en el art. 5 que «Las autoridades eclesiásticas se han de comprometer con quienes afirman haber sido afectados, junto con sus familias, para que sean tratados con dignidad y respeto», añadiendo que

24 Ver la nota 4.

25 "Protocolo de actuación de la Iglesia en España para tratar los casos de los delitos más graves cometidos contra la moral por parte de clérigos, Conferencia Episcopal Española, visitado en septiembre de 2019, https://www.conferenciaepiscopal. es/wp-content/uploads/2015/02/Imagenes_2015_Protocolo_Canonico.pdf; “Protocolo de actuación según la legislación del Estado”, Conferencia Episcopal Española, visitado en septiembre de 2019, https:/www.conferenciaepiscopal.es/wp-content/ uploads/2015/02/Imagenes_2015_Protocolo_Civil.pdf

$26 \mathrm{Al}$ menos en las versiones francesa y portuguesa se emplea aquí un término (bureau, repartiçāo) que tiene ese sentido, y no el más convencional de «oficio» (desempeñado por una sola persona) que aparece en la versión española.

27 Se puede apreciar la sensibilidad a estas cuestiones en algunos puntos del apartado 9 del mencionado documento de la Comisión Pontificia para la Protección de menores. Se entiende que para todo ello se presta mejor un equipo de personas que una sola detentando un oficio. 
se les ofrezca acogida, escucha, seguimiento, atención espiritual e incluso médica, terapéutica y psicológica si fuera el caso, y que se debe proteger su imagen, su privacidad y la confidencialidad de sus datos ${ }^{28}$. Por su parte, el art. 4 §2 prohíbe causar ningún perjuicio, como «represalias o discriminaciones», a quien haya "presentado un informe», y añade que hacer esto podría incurrir en una conducta del art. $1 \S 1$ b. En todo caso, y como es lógico, la norma deja fuera de esta protección al informante el supuesto del c. 1390, donde el CIC tipifica como delito el hecho de presentar una denuncia falsa ante la autoridad eclesiástica acusando a alguien de haber cometido un delito canónico, e incluso el de lesionar «de otro modo» la buena fama de alguien; dos circunstancias que, con los matices que las distinguen, podrían darse en el marco de la regulación que hace el m. p. sobre la información de los distintos hechos y conductas a los que se refiere ${ }^{29}$.

A continuación, el art. 4 §3 también prohíbe que se imponga «al que haga un informe [...] alguna obligación de guardar silencio con respecto al contenido del mismo». Se ve que aquí el m. p. quiere hacerse cargo de uno de los aspectos más duramente censurados a la Iglesia en su manera de haber tratado los casos de abuso sexual a menores de edad, que ha sido el de mantenerlos en secreto llegando para ello a plantear a las víctimas (o a quien informara del caso, como puede ser la propia familia) que guardaran silencio y no dieran a conocer el caso a nadie más,

${ }^{28}$ Ciñéndonos al ámbito del derecho canónico penal (es decir, a los hechos y conductas tipificados como delito) VELM completa con este tipo de aportaciones que vamos viendo la muy escasa referencia que hace el CIC a la recepción de la «noticia del delito» (c. 1717 §1), tratada no obstante con cierta amplitud por diversos autores, cf., p. ej., Marino Mosconi, "L'indagine previa el'aplicazione della pena in via amministrativa”, en I giudizi nella Chiesa. Processi e procedure speciali, dir. Gruppo Italiano Docenti di Diritto Canonico - Associazione Canonistica Italiana (Milano: Glossa, 1999), 193-195.

${ }^{29}$ También puede darse el delito de falsedad documental del c. 1391, supuesto que el informe es un escrito como parece sería en VELM. Conviene aclarar que se incurre en el delito del c. 1390 cuando se acusa en falso de una manera deliberada, sabiendo que no es verdad lo que se comunica, cf. Antonio Calabrese, Diritto penale canonico, 2. ${ }^{a}$ ed. (Città del Vaticano: Librería Editrice Vaticana, 1996), 336-337. Esto debe impedir que la lógica excepción que hace la norma del supuesto del c. 1390 disuada de informar según los propósitos de VELM — perjudicando su intención de fomentar y favorecer que se haga- cohibiendo de hacerlo por temor a incurrir en delito si no se tiene entera seguridad sobre la verdad de determinados hechos y conductas contemplados en el m. p. 
incluso presionando para que así fuera ${ }^{30}$. La disposición no impide en sí misma que el informante decida qué hacer en este aspecto, y habría de entenderse en el marco de otro punto con el cual VELM pretende no entrar en conflicto, que sería la obligación que pueda haber en algunos ordenamientos estatales de comunicar a las autoridades estos casos. El art. 19 se hace cargo de esta cuestión, disponiendo que el m. p. se ha de aplicar sin perjuicio de lo dispuesto en las «leyes estatales, en particular las relativas a eventuales obligaciones de informar a las autoridades civiles competentes»; lo cual afecta a todos los ciudadanos del Estado incluidos, obviamente, los religiosos y clérigos, con algunas particularidades que pudieran darse en ellos (volveremos más adelante sobre esta cuestión).

En cuanto al contenido del informe, el art. $3 \S 4$ lo plantea con un nivel de detalle que incluya pormenores «como indicaciones del tiempo y lugar de los hechos, de las personas involucradas o con conocimiento de los mismos, así como cualquier otra circunstancia que pueda ser útil para asegurar una valoración precisa de los hechos» ${ }^{31}$. Parece claro que se pretende disponer de un informe por escrito, y quizá convendrá aclarar (por ejemplo, en el diseño que se haga sobre el modo de proceder en las oficinas que se constituyan) que pueda aceptarse el caso de que el informante no lleve redactado un informe así, sino que acabe elaborándose con datos que aporte verbalmente ${ }^{32}$.

${ }^{30}$ Cf. Nicholas P. Cafardi, "Stones Instead of Bread: Sexually Abusive Priests in Ministry”, Studia Canonica 27 (1993), 146; ABC del 5/6/02, 33; El Mundo del 5/6/02, 30; El País del 14/6/02, 30; Il Regno del 15/4/02, 228-229. Quizá hubiera tenido mucho sentido que el m. p. integrara en lo dispuesto por el art. 4 \$2 el incumplimiento de esta prohibición, pues parece claro que podría fácilmente responder a una conducta que interfiere o elude la investigación del caso según se refiere a ello el art. 1 §1b.

${ }^{31} \mathrm{El} \mathrm{m}$. p. pasa por alto especificar el supuesto de información que se presente de manera anónima. Esto tampoco se hace, dentro del ámbito concreto del derecho penal, con respecto a la noticia del delito de la que se hizo mención más arriba, y la doctrina tiende a decir que si es anónima y le faltan datos importantes no se le debe dar crédito, cf., p. ej., William H. Woestman, Ecclesiastical Sanctions and the Penal Process (Otawa: Saint Paul University, 2003), 161; Bruno F. Pighin, Diritto penale canonico (Venezia: Marcianum Press, 2008), 534.

32 La idea sería que elementos como la mención al c. 1390 apenas comentada o ahora la posible interpretación de que se exige presentar un informe escrito y detallado, no disuadan de dar la información a la que se refiere el m. p. a quien, en este caso, no esté en condiciones de elaborar previamente y por sí mismo un informe así. Seguramente será mejor integrar sus disposiciones de la manera más conveniente en manuales de procedimiento para las oficinas y encargados de recibir informes o en 
Digamos, finalmente, que el art. $2 \S 2$ ofrece un nuevo elemento de garantía y protección que favorezca la presentación de información estableciendo que esta debe ser tratada de manera que «se garantice su seguridad, integridad y confidencialidad», remitiéndose al c. 471.2. Conforme a este canon, cabe entender que la norma se dirige a quienes accedan a la información por tener asignadas tareas de recepción de la misma, imponiéndoles el deber de guardar secreto sobre ello. Se entiende que esto habrá de observarse sin perjuicio de transmitir la información según el propio m. p. dispone que ha de hacerse (entraremos enseguida en este punto), lo cual habrá de incluir las obligaciones que imponga el ordenamiento estatal en este punto según acabamos de ver.

\subsection{QUIÉN INFORMA Y A QUIÉN LLEGARÁ LA INFORMACIÓN}

Además de potenciar que se aporte información sobre los hechos y conductas del art. 1 mediante la obligación de implantar procedimientos para hacerlo y distintos elementos que generan un entorno propicio a la presentación de informes, el m. p. contiene diversas disposiciones acerca de quién informa y sobre a quién llegará finalmente esa información.

\subsubsection{Cualquier persona}

$\mathrm{El}$ art. 3 §2 establece que «cualquier persona puede presentar un informe sobre las conductas mencionadas en el artículo 1, utilizando los procedimientos indicados en el artículo anterior o cualquier otro modo adecuado", procedimientos que a todas luces se han de referir al oficio-oficina que, como se ha visto, manda establecer el art. $2 \S 1^{33}$. La norma no impone aquí ninguna obligación de informar (como enseguida

información que se haga llegar «al público» (por retomar la expresión del art. 2 §1 ya recogida aquí más arriba), de modo que quede a salvo el cumplimiento de dichas disposiciones en el momento y modo adecuados — quizá sin necesidad de hacer mención explícita o detallada de las mismas-y se dé prioridad a que la información será recibida en un clima de acogida y ayuda.

33 Aunque el art. 1 usa el término «conductas» solo para lo que recoge en el $\S 1 \mathrm{~b}$, se diría que en este art. 3 §2 se sobreentiende que cualquier persona puede también presentar un informe sobre los hechos del art. 1 §1a «utilizando» ese oficio-oficina, pues apenas tendría sentido obligar a generarlo solo para informes sobre lo recogido en el art. $1 \S 1 b$. 
veremos que sí se hace en otro lugar del m. p.) sino que se mantiene en el contexto de facilitar que se haga. La posibilidad de recurrir a otro medio que no sean los sistemas a los que se refiere el art. 2 §1 no quita ninguna fuerza al carácter obligatorio que allí se dio a su establecimiento, ni debería verse como una devaluación de su importancia y utilidad. El m. p. pretende potenciar la posibilidad de que cualquier persona informe, y parece claro que para los fieles en general (si no tienen especial conocimiento y experiencia sobre las estructuras de la Iglesia en estos niveles) la ausencia de sistemas así - con todo lo que ha de rodearles en cuanto a darlos a conocer y motivar para que se recurra a ellos- es un serio obstáculo para que den el paso de aportar la información que tengan; pero tampoco sería adecuado cerrar el camino a otro modo de informar.

En cuanto al destino del informe en el marco de este amplio espacio de su posible procedencia, que abarca a «cualquier persona», interesa atender a tres disposiciones de VELM:

art. 2 §3. Con excepción de lo establecido en el art. 3 §3, el ordinario que ha recibido el informe lo transmitirá sin demora al ordinario del lugar donde habrían tenido lugar los hechos, así como al ordinario propio de la persona señalada.

art. 3 §3. Cuando el informe se refiere a una de las personas indicadas en el art. 6, ha de ser dirigido a la autoridad correspondiente según los artículos 8 y 9. En todo caso, el informe siempre se puede enviar a la Santa Sede, directamente o a través del representante pontificio.

art. 8 §1. La autoridad que recibe un informe lo transmite tanto a la Santa Sede como al metropolitano de la provincia eclesiástica en la que está domiciliada la persona señalada.

§2. Si el informe se refiere al metropolitano o si la Sede Metropolitana está vacante, se envía tanto a la Santa Sede, como al obispo sufragáneo con mayor antigüedad en el cargo a quien, en este caso, se aplican las disposiciones siguientes relativas al metropolitano. §3. Cuando el informe se refiera a un legado pontificio, se transmite directamente a la Secretaría de Estado.

En cuanto al «ordinario», digamos que según el c. 134 el obispo diocesano es el ordinario de esa diócesis y también es «ordinario del lugar» de la misma, término que se aplica, asimismo, a sus cargos de confianza 
conocidos como vicario general y vicario episcopal ${ }^{34}$; y en los IR clericales de derecho pontificio son ordinarios también (pero no «del lugar») los superiores mayores (SM); es decir, el superior general (lo es de todos los miembros del IR) y los superiores provinciales (lo son solo de los miembros de su Provincia) ${ }^{35}$. Por lo que toca al ordinario propio de «la persona señalada» (cabe entender, personas del art. 6 u otro clérigo o religioso/a sobre quien se informe de haber llevado a cabo hechos o conductas del art. 1; por tanto, y según se dijo antes, conductas del §1b en el caso de las primeras o hechos del §1a en todos los supuestos) para los miembros de un IR clerical de derecho pontificio este ordinario sería el superior general o el superior provincial de la Provincia a la que pertenece, mientras que el obispo diocesano es «ordinario propio» de los miembros de su diócesis ${ }^{36}$. Por lo que se refiere al «metropolitano» y al «obispo sufragáneo», esto hace referencia a las Provincias Eclesiásticas, que son agrupaciones de varias diócesis (c. 431 §1) en las que una de ellas es la "Sede Metropolitana» y su obispo (que tiene título de arzobispo) es el metropolita (o metropolitano), el cual tiene algunas facultades en la toda la Provincia (cc. 435-438) que no tienen los obispos «sufragáneos»; es decir, los obispos de las demás diócesis de la misma (diócesis «sufragáneas»).

Como se ve, el art. 2 §3, a la hora de establecer qué se hará con un informe-información que se reciba, parece contar con que haya llegado previamente a manos de un ordinario, del cual no da más especificaciones. Conectando esta disposición con los citados art. 3 §2 y art. $2 \S 1$, cabe entender que aquí se está pensando básicamente en quien sea ordinario en la diócesis (el obispo o algún vicario) en cuyo ámbito esté y opere el «sistema» u oficio-oficina al que se refiere el art. 2 §1 (se diría que los modos de proceder que se establezcan contemplarán que el informe llegue a manos de alguno de ellos); pero también es verdad, como hemos visto, que el art. 3 \$2 contempla la posibilidad de que la información se

\footnotetext{
${ }^{34}$ El vicario general ejerce sus funciones en todo el territorio de la diócesis, y el episcopal solo en una jurisdicción más reducida dentro de la misma, sea un territorio o sea determinada por algún otro criterio (c. 479).

35 Ver las notas 13-15 y 17. El c. 134 asocia el término «ordinario» al «superior mayor» de un IR, que se refiere (cc. 621-622) a los dos cargos mencionados (general y provincial).

${ }^{36}$ Háganse aquí las equiparaciones que ya se comentaron, conforme a los cc. 368,372 y $294-297$.
} 
aporte por cualquier otro cauce. En este sentido, la opción por referirse al ordinario en el art. 2 \$3 incluye, según hemos dicho, a los SM de los IR clericales de derecho pontificio, y es un hecho que algunos de ellos van creando sistemas-oficinas como los contemplados en el art. 2 §1 (lo cual es compatible con la obligación de establecerlos que allí se impone a las diócesis) ${ }^{37}$. Según esto, que la información llegue a través de este cauce a un superior provincial o al superior general de estos IR encaja con el art. $2 \S 3^{38}$.

En cuanto a qué hará con un informe recibido el ordinario a cuyas manos llegue, vemos que el art. 2 §3 se remite en primer lugar al art. 3 $\S 3$, y que este nos sitúa ante el hecho de que la información se refiera a las personas mencionadas en el art. 6; es decir, obispos, cardenales, legados, así como clérigos que están o han estado encargados del gobierno pastoral de una diócesis o entidad asimilada o de una Prelatura personal y moderadores supremos (superior/a general) que lo son o lo han sido de un IR de derecho pontificio (por tanto, clericales o laicales, y en estos últimos tanto masculinos como femeninos), sea que la información se refiere a hechos del art. $1 \S 1$ a como si hace referencia a conductas del art. $1 \S 1 \mathrm{~b}$, con el matiz para estas últimas de que en el caso de los clérigos y moderadores sean conductas llevadas a cabo durante munere. Vemos que el art. 3 §3 prevé como posibilidad en esos casos que la información se haga llegar a la Santa Sede directamente o a través del legado, si bien dispone previamente que se debe remitir a la «autoridad» mencionada en el art. 8 (de nuevo simplificamos prescindiendo del art. 9, que se refiere a las Iglesias católico-orientales), el cual habla a su vez en el §1 de una «autoridad» que haya recibido el informe disponiendo lo que habrá

37 Cf. "Los jesuitas de Madrid crean una nueva 'Comisión de escucha' para acoger, escuchar y apoyar a las víctimas de abuso sexual”, Religión Digital, visitado en septiembre de 2019, https://www. religiondigital.org/vida-religiosa/jesuitas-Madrid-Comision-escuchar-victimas-religion-comillas-educacionmenor es_0_2101589832.html

38 Puede que el m. p. no llegue a dejar del todo claro cómo han de proceder, no siendo ordinarios, los superiores de IR clericales diocesanos y los superiores y superioras de IR laicales (de derecho diocesano o pontificio) a los que llegue información; cosa que no hay que descartar, especialmente si se refiere a miembros de su propio IR, como fruto de una acción espontánea y fácilmente comprensible de quien disponga en ese caso de una información así. Cabría pensar que estos superiores/as siempre pueden hacerla llegar al sistema u oficina diocesanos que se haya implementado, con lo cual llegaría a manos de un ordinario de la diócesis. 
de hacer ${ }^{39}$. Aquí nos encontramos, a juzgar por el tenor literal del texto, con que remitir a la Santa Sede el informe sobre una persona del art. 6, más que una posibilidad (como se diría que lo contempla el art. 3 §3) es algo que se ha de hacer, además de tener que remitirlo «al Metropolitano de la Provincia eclesiástica en la que está domiciliada la persona señalada ${ }^{40}$; y si se refiere al propio metropolita o está vacante la Sede Metropolitana, este envío se hace al obispo sufragáneo más antiguo en el cargo (§2), disponiendo la norma que si la información hace referencia al legado se habrá de remitir directamente a la Secretaría de Estado $(\S 3)^{41}$.

Fuera del caso en que el informe se refiera a persona del art. 6 (por tanto, cuando haga referencia a hechos del art. $1 \S 1 \mathrm{a}$-que tienen

${ }^{39}$ Como el art. $8 \S 1$ dice «autoridad» que ha recibido el informe y no «ordinario», cabría pensar que, si es un informe sobre persona del art. 6, un superior de IR clerical diocesano o un superior/a de un IR laical al que haya llegado (ver la nota 39) podría proceder directamente conforme al art. 8 sin pasar por un ordinario. La idea podría ser que ellos/as sí responden al concepto de «autoridad» aunque no sean ordinarios; pero quizá hubiera sido más sencillo que el art. $8 \S 1$ se refiriera al ordinario que recibe un informe y no a la «autoridad». Con ello hubiera conectado mejor con el punto de partida del art. $2 \S 3$ por cuanto este lo expresa como «Ordinario que ha recibido el informe»; y también con el sentido del término «autoridad» del art. $3 \S 3$, donde parece claro que se refiere al metropolitano al cual ha de remitirse el informe cuando se refiere a personas del art. 6 (como enseguida se verá que continúa diciendo el propio art. 8 §1). Por otro lado, no se acaba de entender bien por qué el art. 8, encabezando los tres párrafos que desglosan su contenido, dice "Procedimiento aplicable en el caso de un informe sobre un Obispo de la Iglesia latina», cuando se ve que el art. $3 \S 3$ se remite a él para el supuesto de que un informe se refiera a una persona del art. 6 , donde también se contemplan personas que no son obispos.

40 Se sobreentiende que si el arzobispo de la Provincia del domicilio es el ordinario al que llegó el informe, este paso del art. 8 §1 de enviarlo al metropolita ya está por sí mismo cubierto. Sobre la adquisición y pérdida de un domicilio, ver los cc. 102, 103 y 106. Como se ve, en la Iglesia es posible tener más de un domicilio, lo cual podría complicar las cosas en la aplicación de este paso (aquí no se va a entrar en esta cuestión).

41 Sobre este singular e importante dicasterio de la Curia Romana se trata en los nn. 39-47 de la Constitución Apostólica de 1988 Pastor bonus, cf. AAS 80 (1988): 841930. El hecho de que tenga una «sección segunda» (nn. 45-47) para la relación con los Estados da mayor sentido a que esté contemplada como destinataria de la información referida al legado, si bien ya se dijo (ver la nota 7) que puede haber legados con función de representar al papa ante las Iglesias particulares y las autoridades estatales de una nación, pero también legados que solo le representan ante las primeras. En cuanto al destinatario del informe en los demás casos, dentro de la estructura de organismos de la Santa Sede, se entiende que este punto habrá que guiarse por el art. 7, del cual se hablará más adelante. 
contenido o connotación sexual directa- cometidos por cualquier otro clérigo o religioso/a de cualquier tipo de IR) el art. 2 \$3 dispone, como se ve en la anterior transcripción de la norma, que el ordinario que lo recibe «lo transmitirá sin demora al Ordinario del lugar donde habrían tenido lugar los hechos, así como al Ordinario propio de la persona señalada ${ }^{42}$. Según lo explicado más arriba, siempre habrá un "ordinario del lugar» para cualquier sitio donde se hayan dado los hechos de los que se informe (sería el obispo diocesano o su equiparado según los cc. 368 y 381 §2, o un vicario general o episcopal) con lo cual siempre es posible atender esta parte de la norma. Sin embargo, en cuanto al «ordinario propio de la persona señalada» nos encontramos de nuevo con que en el caso de los IR solo son ordinarios propios de sus miembros los SM (provinciales o general) de los IR clericales de derecho pontificio. Cabría entender que si la información se refiere a un religioso de IR clerical de derecho diocesano, o a un religioso/a de un IR laical, bastaría con proceder a remitirla al ordinario del lugar donde se dieran los hechos de los que se informe ${ }^{43}$.

\subsubsection{Clérigos y religiosos}

Aparte de la posibilidad de informar ofrecida en el art. $3 \S 2$, como acabamos de ver, a «cualquier persona», el art. $3 \S 1$ establece previamente una auténtica obligación jurídica de hacerlo que recae sobre todo clérigo y todo miembro de cualquier tipo de IR (de derecho pontificio o

${ }_{42}$ El ordinario que tiene el informe puede ser a la vez uno u otro de los ordinarios aquí contemplados, y podría ser los dos; por ejemplo, el obispo diocesano en el caso de un clérigo de su diócesis del que se informa sobre hechos acaecidos en la misma. En estos casos también se sobreentiende que uno de los pasos aquí contemplados, o los dos, ya está en sí mismo cubierto.

${ }^{43} \mathrm{El}$ art. 2 §, junto con el art. 3 §, podría comportar que se dé curso (por así decir) al informe-información sobre un religioso/a de IR laical (o clerical de derecho diocesano) al ordinario del lugar de los hechos (desde el sistema-oficina diocesano o desde otro origen) sin pasar por ningún superior/a del instituto, dado que no son ordinarios de ningún tipo. Teniendo en cuenta la entidad de muchos IR laicales y su ingente actividad (educativa, sanitaria, asistencial, misionera, etc.) quizá hubiera sido mejor evitar esta posibilidad y disponer las cosas de modo que quedase más asegurado que la información llega en estos casos a los superiores/as del IR. Ya se dijo que el m. p. da pie a que les pueda llegar (ver la nota 38); pero vemos que también podría no llegarles, al menos en unos primeros momentos. 
diocesano, clerical o laical, masculino o femenino), como ha de entenderse partiendo de que el texto no hace ninguna matización a este respecto (sí las hace con relación a otros puntos, como se ha ido viendo, pero aquí no). La obligación se refiere - con una excepción referida al c. 1548 de la cual se tratará aquí más adelante- a informar «sin demora» de «los hechos mencionados en el art. 1», con lo cual habrá que entender que incluye lo contemplado en el §1a de dicho artículo (hechos que en sí mismos tienen un contenido sexual, con las precisiones aportadas sobre ello en el §2) tanto si se refiere a personas del art. 6 como si hacen referencia a cualquier otro clérigo o religioso/a (aquí también, de cualquier tipo de IR), así como incluye lo contemplado en el $\S 1$ b, del cual ya sabemos que integra en VELM conductas que menciona dicha letra (de interferir o eludir la investigación de hechos de la letra anterior) solo cuando han sido llevadas a cabo por personas del art. 6 y con la limitación en algunos casos de que haya sido durante munere ${ }^{44}$. La obligación no se da solo cuando el clérigo o religioso/a «tenga noticia» de algo sobre lo cual se le obliga a informar, sino también cuando tenga «motivos fundados para creer» que ha sucedido ${ }^{45}$.

El diseño de esta obligación se completa estableciendo el propio art. 3 \$1 que el clérigo o religioso/a hará llegar la información «al ordinario del lugar donde habrían ocurrido los hechos o a otro ordinario de entre

${ }^{44}$ En este caso, al referirse a los «hechos» del art. 1 se podría entender que la obligación para los clérigos y religiosos recae solo sobre informar de lo recogido en el §1a por ser a lo que dicho artículo se refiere con ese término, de modo que no sería obligatorio informar sobre lo recogido en el $\S 1$ b porque es a lo que el art. 1 se refiere como «conductas». En todo caso, a la luz de lo expresado en la nota 33, se diría que aquí el m. p. no pretende limitarse solo al art. 1 §1a, sino abarcar en la obligación el conjunto del art. 1 (también las malas «conductas» de gobierno del §1b); y en todo caso, aun cuando se quisiera interpretar lo contrario, quedaría que informar los clérigos y religiosos sobre lo recogido en el $§ 1 \mathrm{~b}$ es algo que siempre pueden hacer, aunque no fuera obligatorio, pues es evidente que no se les prohíbe hacerlo.

45 Esta matización podría ponerse en la línea de lo expresado más arriba en la nota 29. A salvo de una lectura más lúcida de VELM y de un juicio más acertado sobre su contenido, se diría que los distintos matices y puntualizaciones que se van haciendo a lo largo del texto (acerca de personas y cargos, de hechos y conductas según quién los hubiere llevado a cabo, etc.) podrían desplegar una casuística muy amplia con diversos supuestos para los que correspondería una u otra manera de aplicar el m. p., habiendo quizá algunos para los que no haya una previsión del todo clara y completa. Aquí se van abordando algunos, sin pretender un tratamiento enteramente exhaustivo de esta cuestión. 
los mencionados en los cánones 134 CIC [...] sin perjuicio de lo establecido en el §3 del presente artículo»; o sea, en el ya mencionado anteriormente art. $3 \S 3$. Se diría que transmitir en los términos del art. 8 la información recibida sobre hechos o conductas del art. 1 §1a y §1b llevados a cabo por personas del art. 6 - es decir, transmitirla a la Santa Sede y al Metropolitano que corresponda según el domicilio, pues ya se vio que a esto se refiere el art. $3 \S 3$ remitiéndose al art. 8- no está previsto tanto como algo que haga directamente el clérigo o religioso/a que tiene la información, sino que este/a la hará llegar a un ordinario de los aquí mencionados que será quien procedería conforme al art. 8. En cuanto a este ordinario al cual hará llegar la información el clérigo o religioso/a vemos que puede ser el del lugar de los hechos u otro.

Esta disposición no es como la del art. $2 \S 3$, que, como vimos, garantiza que la información llegue a manos tanto del ordinario del lugar de los hechos como del ordinario propio de la persona sobre la cual se informa. En cambio, el art. $3 \S 1$ se formula ofreciendo al clérigo o religioso/a las alternativas de trasmitir la información al ordinario del lugar de los hechos o a cualquier otro (decir que sea de los mencionados en el c. 134 no añade mayor precisión); y se diría que no queda excluida como posibilidad que presente un informe en el sistema-oficina que haya en la diócesis, supuesto que el art. 3 \$2 permite hacerlo a cualquier persona. Quizá el texto debiera haber definido mejor este paso (hay innumerables ordinarios a los que no tiene sentido transmitir esta información), pero siempre cabe pensar en maneras de concretar lo impreciso de esta disposición que tengan más sentido. Por ejemplo, parece razonable mantener que la información llegue al ordinario del lugar de los hechos y al propio de la persona sobre la cual se informa, o que un clérigo diocesano (el que no pertenece a un IR) presente un informe a su propio obispo (por ser su ordinario) o a través del sistema-oficina de su diócesis (que verosímilmente lo hará llegar a un ordinario de la misma que atendería a las disposiciones del m. p. en cuanto al flujo de la información), o que un religioso/a la presente a su propio superior/a y que sea este/a quien proceda según los propósitos y disposiciones de VELM ${ }^{46}$. Se puede pen-

${ }^{46} \mathrm{Si}$ se trata de un IR clerical de derecho diocesano o de un IR laical, el religioso/a no se ajustaría con este paso a la letra del art. $3 \S 1$, pues este pide transmitir la información a un ordinario y ya hemos dicho que en estos IR el superior/a no lo es. Con todo, cabe mantener que sea una manera adecuada de proceder. El m. p. abarcaría la posibilidad de que cualquier religioso/a informe directamente al ordinario del 
sar en otras maneras adecuadas de proceder, y cabe suponer que habrá documentos internos en los cuales se pueda precisar este punto.

\section{DESLINDE DE HECHOS Y CONDUCTAS}

Una vez que la información llegue a los destinatarios previstos, el m. p. dispone que estos «procederán en conformidad con el Derecho de acuerdo con lo previsto para el caso específico». Así dice el art. $3 \S 3$, y se entiende que la disposición se refiere a cualquier caso y supuesto. Por tanto, se asume que no todos ellos tienen el mismo tratamiento previsto en el derecho, y aquí cobra especial interés poner esta cuestión en relación con el derecho penal de la Iglesia.

Hay supuestos del art. 1 §1a que son delitos canónicos desde antes del m. p. Así, el c. 1395 §2 tipifica como delito, estableciendo para él una pena, el que cometa un clérigo «contra el sexto mandamiento del Decálogo» con un menor de edad, al cual se suele hacer referencia como «abuso sexual de un menor» por parte de un clérigo. El canon perfila el tipo penal fijando que la víctima sea menor en 16 años, pero desde 2001 también es delito si tiene entre 16 y 18 años $^{47}$. Es lo que resulta del art. $4 \S 1$ de las normas sobre delitos «más graves» y por ello reservados a la CDF que se aprobaron el 30 de abril de ese año mediante el m. p. de Juan Pablo II $S a$ cramentorum sanctitatis tutela, el cual fija la edad del menor en 18 años ${ }^{48}$. El hecho de que el delito pasara, junto con otros, a tener la condición de reservado a la CDF comporta básicamente que se debe remitir el caso a la congregación y aplicarle las disposiciones de esas normas, las cuales

\footnotetext{
lugar sin pasar por ninguno de sus superiores/as (ni siquiera los SM de IR clerical de derecho pontificio son «ordinario del lugar»), pero esto no parece lo más acorde a las características de la vida religiosa; mucho menos si se tratara de informar sobre un miembro del propio instituto.

47 Esto ya era así en EE. UU. desde 1994, merced a la concesión de Juan Pablo II a la petición que planteó la Conferencia Episcopal de ese país, cf. Woestman, Ecclesiastical Sanctions, 270-271.

${ }^{48}$ Para una versión española de estas normas de 2001, cf. Federico Aznar, Delitos de los clérigos contra el sexto mandamiento (Salamanca: UPSA, 2005), 95-119. Para una versión inglesa, cf. Woestman, Ecclesiastical Sanctions, 303-309; para una italiana, cf. Pighin, 605-611. Por remitir a algún trabajo sobre estas normas, cf. Velasio de Paolis, "Norme de gravioribus delictis riservati alla Congregazione per la Dottrina della Fede”, Periodica 91 (2002): 286-289.
} 
difieren en algunos puntos con lo previsto en el CIC. Estas normas de 2001 fueron sustituidas por otras para delitos «más graves» reservados a la CDF del año 2010 (21 de mayo), que contemplan un nuevo tratamiento para los mismos y en su art. $6 \$ 1.1$ mantienen entre ellos el abuso sexual cometido por un clérigo con un menor de 18 años $^{49}$.

Si cotejamos lo anterior con el apartado II del art. 1 §1 a de VELM —más arriba se transcribieron las letras a y b de ese párrafo- podemos fácilmente reconocer que el hecho de «realizar actos sexuales con un menor» allí contemplado está en el tipo penal apenas mencionado del c. 1395 §2 y las normas para delitos reservados a la CDF. Sin embargo, no podemos decir que lo estén todos los casos recogidos en ese apartado II, pues, como ya se vio, el art. $1 \S 1 \mathrm{del} \mathrm{m}$. p. integra ese hecho tanto si lo lleva a cabo un clérigo como si lo hace cualquier religiosa o religioso que no lo sea, y sin embargo en el c. 1395 §2 y en las normas de 2010 solo son delito si el autor es un miembro del clero.

Por otro lado, merced al mismo art. $6 \S 1.1$ de las mencionadas normas de 2010, a partir de ese año quedó tipificado como delito (y reservado a la CDF) el cometido «contra el sexto mandamiento» por un clérigo con una persona adulta «que habitualmente tiene uso imperfecto de razón», lo cual es lógico poner en relación con el supuesto de actos sexuales realizados con «persona vulnerable» (añádase mayor de 18 años) que igualmente podemos ver en el apartado II del art. 1 \$1a del m. p. y que, como ya se mostró, aparece explicado en el $\$ 2$ cuando dice que «a efectos de las presentes normas» se ha de entender como «cualquier persona en estado de enfermedad, de deficiencia física o psicológica, o de privación de la libertad personal que, de hecho, limite incluso ocasionalmente su capacidad de entender o de querer o, en cualquier caso, de resistir a la ofensa ${ }^{50}$. No es objeto de este trabajo entrar a estudiar ninguno de estos

49 Para estas normas de 2010, cf. AAS 102 (2010): 419-431. Aquí no se va a entrar en el tratamiento especial que prevén para los delitos reservados. Para algunos trabajos sobre las mismas, cf. Federico Aznar, “Los 'delicta graviora' reservados a la Congregación para la Doctrina de la Fe: Texto modificado (2019), REDC 68 (2011): 283-313; José Luis Sánchez-Girón, "Delitos contemplados en las normas de gravioribus delictis del año 2010", Estudios Eclesiásticos 85 (2010): 371-367; “Normas procesales en la regulación de gravioribus delictis del año 2010", Estudios Eclesiásticos 86 (2011): 171-747.

50 También aquí hay que entender que se refiere a una persona adulta, pues en ambos casos si tuviera menos de 18 años el supuesto ya estaría recogido bajo cualquier hipótesis en el del menor de edad. 
$\operatorname{conceptos}^{51}$, pero sí hacer notar que lo recogido en el m. p. desborda el tipo penal del nuevo delito de 2010 (baste comparar, entre otras cosas, el elemento «incluso ocasionalmente» del primero con el de «habitualmente» en el segundo). Resulta claro que tener habitualmente uso imperfecto de razón queda comprendido en lo que VELM entiende por persona vulnerable, pero también se ve que esto comprende toda una serie de supuestos que no eran delito al entrar en vigor el m. p. por no tener cabida en el mencionado tipo penal. Esta mayor amplitud del m. p. se da en dos niveles. El primero sería que, en el caso de persona que tiene habitualmente uso imperfecto de razón, el tipo penal solo comprende el supuesto de que sea un clérigo (diocesano o de IR) quien realice un acto sexual con ella, mientras que en el apartado II estarían también comprendidos los realizados por un religioso no clérigo o una religiosa. El segundo sería, en el caso de cualquier clérigo o religioso/a, el de actos sexuales realizados con otra persona vulnerable; es decir, con persona vulnerable que no tiene habitualmente uso imperfecto de razón: no responden al tipo penal del nuevo delito de las normas de 2010, pero son hechos que sí están contemplados en VELM ${ }^{52}$.

También el apartado I del art. 1 §1a merece atención, si cotejamos el hecho allí recogido de "obligar a alguien, con violencia o amenaza o mediante abuso de autoridad, a realizar o sufrir actos sexuales» con el tipo penal del delito contra el sexto mandamiento cometido por un clérigo cuando lo haya llevado a cabo "con violencia o amenazas o públicamente», tipificado también en el c. 1395 §2; quedando su tipo penal circunscrito, tras el nuevo delito ya mencionado de las normas de 2010, al caso de obrar así contra una persona mayor de 18 años que no tenga habitualmente uso imperfecto de razón, y siendo un delito que no está

${ }^{51}$ Sobre los nuevos tipos penales de las normas de 2010, cf., p. ej., Max Taylor, Ethel Quayle, Child Pornography. An Internet Crime, New York: Brunner-Routledge, 2003; José Bernal, "Delicta graviora", Ius canonicum 50 (2018): 364-365; Ricardo Daniel Medina, "Algunas consideraciones acerca de las modificaciones a las normas de los delitos más graves”, Anuario Argentino de Derecho Canónico 16 (2009-2010): 128-131; Massimo di Veroli, "Pedopornografia: Aspetti tecnico informatici utili all'accertamento delle responsabilità penali da parte dell'autore", en I delitti riservati alla Congregazione, 131-159.

52 Por ejemplo, una persona sana psíquicamente (no tiene habitualmente uso imperfecto de razón) pero que en ese momento está ocasionalmente en una situación que limita su capacidad de entender o de querer o de resistir a la ofensa. 
reservado a la $\mathrm{CDF}^{53}$. De nuevo encontramos que el m. p. hace objeto de sus disposiciones hechos que no están en el c. 1395 §2. Baste con decir que si los hechos de su tipo penal los comete un religioso que no es clérigo o una religiosa estamos en el marco de VELM pero fuera del espacio del canon; y con ver que este no menciona el abuso de autoridad, ante lo cual habría que decir que la sola presencia de este elemento no comporta el delito del c. 1395 §2 del que ahora tratamos ni en el caso del clérigo ni en el del religioso/a ${ }^{54}$.

En cuanto al apartado III del art. $1 \S 1 \mathrm{a}$, los hechos que contiene están en la línea de otro nuevo delito tipificado en el art. $6 \$ 1.2$ de las normas para delitos reservados a la CDF de 2010 que, una vez más, solo es delito

${ }^{53}$ De nuevo resulta que, si fuera un delito cometido con amenazas o violencia o públicamente con persona que tiene menos de 18 años, correspondería al delito reservado a la CDF de abuso sexual a un menor (lo mismo que si no hubiera esos elementos); y si fuera con persona adulta que habitualmente tiene uso imperfecto de razón se correspondería con un delito reservado.

${ }^{54}$ No se ve especial interés en investigar por qué el m. p. integra los supuestos del c. 1395 §2 de usar amenazas o violencia y no el de actuar públicamente, que se asocia a hacerlo en un lugar público o a que el hecho se divulgue, cf. Velasio de Paolis, Davide Cito, Sanzioni nella Chiesa. Commento al Codice di Diritto Canonico Libro VI, 2. ${ }^{\text {a }}$ ed. (Città del Vaticano: Urbaniana University Press, 2001), 360-361. En cuanto a actuar "mediante abuso de autoridad», se podría pensar que estos hechos cometidos con ese elemento sí están tipificados penalmente en el CIC pero en el c. 1389 $\S 1$, por cuanto dispone que comete delito «Quien abusa de la potestad eclesiástica o del cargo». Hay aportaciones acerca de esta norma que quizá permitirían pensar así, aunque no se pronuncian concretamente sobre la integración en este tipo penal de una acción contra el sexto mandamiento llevada a cabo con un abuso de potestad o del cargo; y, a decir verdad, parece que están pensando en acciones propias del ejercicio de una u otro (lo cual obviamente no sería el caso aquí) que se llevan a cabo contraviniendo la ley o los fines que se buscan con él (conceder una dispensa para la que no se está autorizado, etc.), cf., p. ej., Ángel Marzoa, "Comentario al c. 1389", en Comentario exegético... vol. IV/1, 562; Pighin, 439-440. Por otro lado, con una terminología más cercana a la del m. p., el c. $1326 \$ 1.2$ contempla, entre otros «agravantes», que cuando el autor de un delito «abusó de su autoridad» para cometerlo se le «puede castigar con mayor gravedad» de la que tenga la pena establecida para el mismo. Esto podría inclinar a considerar que obligar a realizar o sufrir actos sexuales mediante abuso de autoridad no es delito en el CIC ni en las normas de 2010 (que no lo mencionan) si no concurrió además ningún elemento de los que especifican los tipos penales de los mencionados c. 1395 \$2 y art. 6 §1.1 (menor de edad, mayor de edad que habitualmente tiene uso imperfecto de razón, violencia, amenazas o actuar públicamente); y que el abuso de autoridad entra en juego como agravante cuando alguno de ellos se ha dado. 
en el caso de que lo cometa un clérigo: «La adquisición, retención o divulgación, con un fin libidinoso, de imágenes pornográficas de menores, de edad inferior a 14 años por parte de un clérigo en cualquier forma y con cualquier instrumento». Como se ve en la transcripción aportada más arriba, el m. p. dice aquí «producir, exhibir, poseer o distribuir, incluso por vía telemática, material pornográfico infantil, así como recluir o inducir a un menor o a una persona vulnerable a participar en exhibiciones pornográficas», y explica en el art. 1 §2c qué se entiende por material pornográfico «cualquier representación de un menor, independientemente de los medios utilizados, involucrado en actividades sexuales explícitas, reales o simuladas, y cualquier representación de órganos sexuales de menores con fines predominantemente sexuales». Aunque solo fuera porque integra imágenes de menores con edad entre los 14 y los 18 años (habla solo de «un menor», sin más precisiones sobre la edad) y el tipo penal del mencionado art. $6 \S 1.2$ no lo hace (se refiere a menores de 14 años), vemos que el m. p. incluye hechos que no están en el mismo ni aun cuando los cometa un clérigo. Además, nos encontramos de nuevo con que los supuestos del tipo penal serían objeto del m. p. (que los integra en el campo más amplio que contempla) también cuando se atribuyan a un religioso que no es clérigo o a una religiosa, y en cambio tampoco serían en este caso el delito del art. 6 §1.2 de las normas de 2010.

Por lo que se refiere a las conductas del art. $1 \S 1 \mathrm{~b}$ de interferir o eludir la investigación de los hechos recogidos en art. 1 §1a por parte de las personas mencionadas en el art. 6, se podría decir que sí están tipificadas en el CIC; concretamente en el c. 1389, según el cual, integrando tanto a clérigos como a no clérigos en el tipo penal, comete delito «quien abusa de la potestad o cargo» (\$1) y «quien por negligencia culpable, realiza u omite ilegítimamente, y con daño ajeno, un acto de potestad eclesiástica, del ministerio u otra función» $(\$ 2)^{55}$. En todo caso, bastaría

55 De hecho, sobre la mala gestión que han hecho no pocos obispos de los casos de abuso sexual de menores por miembros del clero procurando el silencio de las víctimas y sus familias, quitando gravedad o credibilidad a sus acusaciones, limitándose a trasladar al clérigo a otro lugar, sin informar allí de lo ocurrido, en el que volvió a delinquir, o cometiendo otros errores así, se ha planteado a veces si no podría considerarse un delito del c. 1389, sea por haber actuado deliberadamente (\$1) o al menos haber ejercido su cargo de manera negligente causando daño ajeno (§2), cf., p. ej., Damián Astigueta, "La persona e i suoi diritti nelle norme sugli abusi sessuali", Periodica 93 (2004), 644; Peter Steinfels, A people adrift, (New York-London: Simon and Schuster, 2003), 46. 
con lo señalado anteriormente sobre el art. 1 §1a para ver que VELM contempla una serie de supuestos que no encajan en el tipo penal de delitos tipificados en el derecho de la Iglesia en 2019, año en el cual el m. p. entra en vigor ${ }^{56}$.

Con respecto a los hechos del art. 1 §1a que están en el tipo penal del c. 1395 §2, se podría alegar que el CIC sí los contempla como delito también en el supuesto de que los lleve a cabo un religioso no clérigo o una religiosa, porque el c. 695 \$1 prevé como causa de expulsión del IR, para cualquier miembro del mismo (clérigo o no), el haber cometido «uno de los delitos de los que se trata en los cc. [...] 1395». Frente al planteamiento de que solo con esto el CIC ya tipifica el supuesto en cuestión como un delito cuya pena sería la expulsión del IR, hay diversas razones para sostener lo contrario ${ }^{57}$.

Pensemos, por ejemplo, que el proceso para la expulsión (c. 695 §2 y cc. 698-700) se encomienda a los superiores del IR, que en los laicales y clericales de derecho diocesano no son ordinarios (como se vio más arriba); ante lo cual tenemos que el CIC contempla el proceso encaminado a «imponer o declarar penas» (c. 1341) —es decir, el «proceso penal» del que trata la Parte IV del L VII (cc. 1717-1731)— como un procedimiento

${ }^{56}$ Hay quien considera que el art. $1 \S 1 \mathrm{~b}$ del m. p. es un «nuevo delito eclesiástico» que denominaríamos "encubrimiento", cf. "Las medidas de la Iglesia en casos de abuso llegan tarde y se quedan cortas", Christoph Strack, visitado en septiembre de 2019, https://www.dw.com/es/las-medidas-de-la-iglesia-en-casos-de-abuso-llegantarde-y-se-quedan-cortas/a-48695433. No obstante, es razonable sostener lo que se ha expresado en la nota anterior; máxime viendo otras explicaciones de expertos canonistas sobre el delito del c. 1389, cf., p. ej., Pighin, 439-443.

57 Para una opinión favorable a que el c. 695 §1 da condición delictiva de lo tipificado en el c. 1395 también cuando lo comete un religioso que no es clérigo o una religiosa, cf. Eduardo Gómez Martín, "El delito contra el sexto mandamiento del Decálogo cometido por un religioso con un menor", REDC 69 (2012): 187-188. Para una contraria, cf. Claudio Papale, "I delitti contro la morale", en I delitti riservati alla Congregazione per la Dottrina della Fede, dir. Andrea D’Auria, y Claudio Papale (Roma: Urbaniana University Press, 2014), 29. Entre otras razones en contra estaría que el supuesto no está en la Parte II del Libro VI del CIC "De las penas para cada uno de los delitos", dedicada por entero a recoger hechos y conductas estableciendo para cada uno de ellos una pena (cc. 1364-1399); o que la expulsión del IR no aparece donde el CIC menciona penas que hay en la Iglesia (cc. 1331-1338). Para mayor tratamiento de la cuestión, cf. José Luis Sánchez-Girón, "La expulsión de un instituto religioso en los cánones 694-700 a la luz de la normativa del CIC en materia penal”, Estudios Eclesiásticos 88 (2013): 699-729. 
en el que siempre interviene un ordinario (cc. 1717-1718) ${ }^{58}$. Además, en un proceso penal, que puede ser judicial o administrativo (cc. 1341, 1718 §1.3), la resolución la adoptan, respectivamente, un juez o tribunal o bien el propio ordinario que lo manda abrir (o un delegado suyo) mediante una decisión personal que debe estar asesorada pero que finalmente es suya (c. 1720.2-3), mientras que la decisión de expulsar del IR se encomienda al superior general del mismo y a los miembros de su consulta para que la tomen mediante votación secreta (c. 699 §1) ${ }^{59}$.

En adelante, aquí se considerará que los mencionados supuestos no están tipificados como delito en el derecho de la Iglesia en el momento de promulgarse VELM, aunque en el CIC sean una causa de expulsión del IR. En caso de sostenerse lo contrario, las consideraciones que siguen se podrán adaptar a ese punto de vista.

\section{4. ¿NUEVOS DELITOS?}

Como hemos visto, el m. p. recoge en su art. 1 §1a una serie de hechos que no eran delito canónico antes de su entrada en vigor. Sin embargo, se puede ver en dicho párrafo que se refiere por dos veces a todos los hechos de esa letra denominándolos «delitos». Se diría que con esto debe bastar para asumir que los que no lo eran en ese momento han pasado a serlo en virtud de VELM; y sin embargo, algunas observaciones sobre cuestiones que quedarían pendientes hacen que tenga sentido cuestionar si es suficiente este mero «nominalismo» (por así decir) para que a un hecho o conducta se le dé en la Iglesia el tratamiento previsto para los delitos ${ }^{60}$.

${ }_{58} \mathrm{El}$ proceso impone la pena que se estableció como pena ferendae sententiae, y declara la que fue establecida como pena latae sententiae (cc. 1314 y 1341). Para más consulta sobre esta cuestión, cf. Claudio Papale, "Latae sententiae", en Diccionario General..., vol. IV, 2012, 975-977.

59 Para una clara opinión de que expulsar del IR no es materia penal, cf. Miquel Pons Portella, "Los supuestos de aplicación extrajudicial de penas en el Derecho Canónico", Ius Canonicum 58 (2018): 124.

${ }^{60}$ En la línea de que pasan a ser delito los supuestos de religiosos no clérigos y religiosas que aquí no se han considerado delictivos antes del m. p., y quizá incluso en favor de que ya lo eran, parecen estar estas declaraciones de Mons. Arrieta: «La novedad aquí es que hasta ahora todos los delitos graves que sabía la Congregación para la Doctrina de la Fe afectan a clérigos, no afectan a religiosos que no sean clérigos o a monjas. Esta nueva ley no ha hecho que los actos de las monjas o clérigos (sic.) sean delitos graves, los delitos graves son solo de clérigos, por ahora. Pero esta 
Una sería, bajo la perspectiva de la aplicación práctica de las normas y las leyes, que la serie de actuaciones contempladas por el derecho canónico penal se pone en marcha al tener noticia de que se ha dado un hecho para el cual esté establecida una pena, y se encaminan hacia el conocimiento de la verdad en torno al mismo para, en su caso, imponerla o declararla en un proceso penal ${ }^{61}$. Según esto, es imprescindible que para ese hecho haya una pena establecida, de modo que bajo el punto de vista aquí adoptado es entonces cuando queda tipificado como delito ${ }^{62}$. Lo que nos encontramos en VELM es que no aparece mencionada pena alguna, de modo que no establece ninguna para los hechos que recoge y no tuvieran ya una establecida en el derecho de la Iglesia con anterioridad; ni tan siquiera mediante una forma bastante frecuente en el CIC que consiste en establecer que el delito sea castigado «conforme a la gravedad» del mismo (por ejemplo, cc. 1388 y 1392) o «con una pena justa» (por ejemplo, cc. 1365, 1376 y 1393), prototipo de lo que se denomina «pena indeterminada» ${ }^{63}$. Por reforzar el argumento cabe decir que en

ley hace que se pueda, que se tengan que denunciar no solamente los de los clérigos sino también los de las monjas y los de los religiosos», cf. «Monseñor Arrieta: el motu proprio "Vos estis lux mundi" es "un paso de la Iglesia para la claridad y la transparencia" ", Rosa Die Alcolea. Se entiende que cuando habla de delitos graves se refiere a delitos reservados a la CDF.

${ }^{61}$ Para las actuaciones penales aludidas ver los cc. 1717-1731 (también, de nuevo, el c. 1341), y en el caso de los delitos reservados a la CDF los artículos 8-31 de las normas de 2010.

62 Tiene pleno sentido abordar una noción de delito desde una perspectiva más elevada, que apele a los fundamentos profundos del derecho canónico y a sus peculiaridades, y que no integre como elemento esencial que haya para él una pena establecida en el derecho positivo; pero el punto de vista práctico y operativo aquí adoptado siempre es importante aun cuando se quisiera tachar de «positivista» —cf. Ángel Marzoa, “Delito”, en Diccionario General..., 2:1026-1029; también, cf. Naaman Boutros, Aspetti giuridico-teologici delle sanzioni e delle pene canoniche alla luce deIl'Ecclesiologia di comunione del Concilio Ecumenico Vaticano II (Tesis doctoral, P. U. Lateranense, 2002), 140-147- y bajo esa óptica es indispensable que haya una pena establecida para que estemos ante un delito, cf. Pighin, 113; Claudio Papale, Il processo penale canonico. Commento al Codice di Diritto Canonico. Libro VI, Parte IV (Città del Vaticao: Urbaniana University Press, 2007), 18; de Palois, Cito, 98-99.

${ }_{63}$ El término aparece en los cc. 1315 y 1349, y quiere decir que la determinación de la pena concreta se deja al criterio justo y proporcional de la autoridad que vaya a imponerla a resultas del proceso penal que se haya llevado a cabo. Cuando la norma ya establece una pena en concreto se dice que la pena es o está «determinada». Sobre estas cuestiones, cf. Pighin, 130. 
los cc. 1364-1399, donde el CIC no recoge sino hechos y conductas que él mismo denomina «delitos» ${ }^{64}$, no aparece ninguno para el cual no se establezca una pena en el canon que lo recoge $\mathrm{e}^{65}$; y esto mismo sucede en las normas sobre delitos reservados a la CDF para todos los que se tipifican en ellas por primera vez en la Iglesia (como algunos de los supuestos mencionados más arriba $)^{66}$.

A decir verdad, y a falta de mejor información y criterio, sería la primera vez (al menos desde el CIC) que un hecho pasa a estar tipificado como delito en la Iglesia con solo denominarlo de ese modo y sin establecer para él una pena ${ }^{67}$. Si solo con eso se abre un proceso penal a un sacerdote que, por ejemplo, realizó un acto sexual con una persona vulnerable, como podría ser por tener una ocasional limitación de su capacidad de querer, pero que no tiene habitualmente uso imperfecto de razón, llegado el momento de imponer la pena, la autoridad competente se encontraría con que el $\mathrm{m}$. p. no le aporta nada al respecto; y también con que al tratarse de una materia penal el c. 19 prohíbe emplear los recursos que allí se ofrecen para resolver que en la ley falte una prescripción expresa acerca de alguna cuestión, como sería acudir a lo establecido en «leyes dadas para casos semejantes» y hacer una aplicación analógica ${ }^{68}$. No podría acudir, por ejemplo, a la pena establecida en

${ }^{64}$ Ver la nota 57.

${ }^{65}$ Fuera de esos cánones el CIC contempla algunos hechos y conductas para los cuales establece una pena (cc. 1457 y 1470), y se podría decir que con ello se incorporan a los delitos tipificados en el derecho de la Iglesia, cf. Sánchez-Girón, "La expulsión", 725. Lo mismo se diga de algunos recogidos en la Constitución Apostólica Universi Dominici gregis - AAS 88 (1996): 305-343- en sus nn. 80 y 81.

${ }_{66}$ Así sucede en los tipos penales mencionados del art. 6 de las normas de 2010; e incluso en uno del art. $3 \S 2$, que recoge un caso del supuesto que el CIC prohíbe con firmeza en el c. 927 pero para el cual no establece una pena (el otro caso, igualmente prohibido por el canon, ya quedó tipificado en el art. 2 §2 de las normas de 2001 también estableciendo la pena allí mismo). Es más, para delitos ya tipificados después del CIC que se recogen entre los reservados a la CDF, las propias normas de 2010 especifican la pena aun cuando ya quedó establecida al tipificarse el delito. Es lo que ocurre con en los art. 5 y 4 §2. Para la tipificación de estos delitos, con su pena establecida, cf., respectivamente, Enchiridion Vaticanum 24 (2007): 1248; AAS 80 (1988): 1367. Para los delitos ya recogidos en el CIC que pasan a estar reservados a la CDF las normas se remiten siempre al canon correspondiente, donde nunca falta la pena establecida.

${ }_{67}$ En las notas anteriores se alude a los delitos que se han tipificado después del CIC y, como se ha señalado, esto nunca se ha hecho sin establecer la pena.

68 Sobre estas cuestiones, cf. Javier Otaduy, "Comentario al c. 18", en Comentario exegético..., 1:372-375. En el campo penal se puede admitir la aplicación analógica 
el art. 6 de las normas de 2010 para el delito del clérigo contra el sexto mandamiento con un adulto que tenga habitualmente uso imperfecto de razón, que permite llegar a imponer una pena de extrema gravedad para los clérigos como es la expulsión del estado clerical, bajo la idea de que se refiere a un caso semejante ${ }^{69}$. Además, aparte de la norma mencionada y en coherencia con ella, el c. 18 impone una interpretación estricta de "las leyes que establecen una pena», lo cual sería un freno a la hora de pretender que el concepto de «persona que habitualmente tiene uso imperfecto de razón» de dicho artículo abarca más casos de los que comprende el propio tenor literal de las palabras ${ }^{70}$.

Por otra parte, VELM tampoco se pronunciaría sobre la condición o no de reservado a la CDF de los que serían nuevos delitos; y salvo mejor opinión, los cc. 18 y 19 volverían a cerrar puertas al intento de solucionar esta cuestión en la línea de lo apenas comentado. No sería este un asunto de menor importancia pues, entre otras cosas, para los delitos reservados el plazo de prescripción de la acción criminal previsto en las normas de 2010 es considerablemente mayor que en el CIC (20 años, según el art. 7), las medidas cautelares del c. 1722 se pueden imponer desde que se abre la investigación (art. 19) y si se sigue un proceso penal administrativo se puede llegar a imponer por decreto la expulsión del estado clerical (art. 21) ${ }^{71}$. Ciertamente, en un

de otras normas en el terreno procesal, pero no en derecho sustantivo como es aquí el caso, cf. Jorge Miras, "Procedimiento administrativo penal", en Diccionario General..., 6:496-497.

69 Para una consideración de la expulsión del estado clerical como una pena de extrema gravedad, cf. Calabrese, 134-135.

${ }^{70}$ Salir al paso de que el m. p. no establece penas pretendiendo algo así como que, "por defecto», en estos casos se entiende establecida "una pena justa», sería inaceptable a menos que se aporte algún fundamento sólido para sostener que se pueda operar así. Como quiera que fuere, en tal caso se habría de asumir que no podría imponerse la expulsión del estado clerical, pues ya se dijo que «una pena justa» es una pena indeterminada y el c. 1349 prohíbe imponer penas perpetuas en esos casos. Sobre la condición de pena perpetua de la expulsión del estado clerical, cf., p. ej., Egidio Miragoli, "La 'pena giusta' nei casi di delicta graviora", Quaderni di diritto ecclesiale 25 (2012): 364-365.

71 Esto no se puede hacer en la regulación codicial en virtud del c. 1342 §2. Sobre las medidas cautelares, el c. 1722 expone los motivos que justifican acudir a ellas y las condiciones en que deben gestionarse, estableciendo que se pueden imponer «en cualquier fase del proceso». Esto significa, a tenor del c. 1718, que la investigación ya está terminada (c. 1718). Para mayor conocimiento sobre esta cuestión, cf. Francisco 
eventual proceso penal que se abriera por algún supuesto de VELM que no fuera delito con anterioridad, la falta de esta determinación no sería tan problemática como la relativa a la pena establecida, pues siempre sería acertado entender que no está reservado a la CDF toda vez que las normas sobre esta materia no recogen esos nuevos supuestos, y no faltaría regulación a la que acudir estando el CIC. En todo caso, sería mejor esclarecer la cuestión que correr el riesgo de interpretaciones desacertadas y de que hubiera procesos que se encaminasen por el cauce que no correspondiera ${ }^{72}$.

A la vista de las cuestiones apenas tratadas, sería razonable esperar que haya ulteriores aclaraciones o especificaciones sobre las mismas. Mientras, quizá lo más prudente sea no dar a los nuevos supuestos el tratamiento previsto en derecho para los delitos, a pesar de que el m. p. los denomine con ese término en el art. 1 (en un sentido más genérico, también se hace en la introducción). Tal vez, y sobre la base de lo señalado,

José Campos Martínez, "Derechos fundamentales del investigado y aplicación de medidas cautelares. Un estudio a partir del art. 19 de las normas sobre delitos más graves”, REDC 74 (2017): 378-392. Para la prescripción de la acción criminal el c. 1362 establece plazos de 3 o 5 años para los delitos que no estén reservados a la CDF. La acción criminal viene a ser un conjunto de actuaciones que la autoridad de la Iglesia realiza con ocasión de un delito, y llegarían en su caso a la imposición de una pena a resultas de un proceso penal. Para una definición de la acción criminal, cf. Hanna G. Alwan, “Acción criminal”, en Diccionario General..., 1:112. Que la acción criminal prescriba, comporta que la autoridad eclesiástica pierde el derecho a llevar a cabo esas actuaciones y ya no podrá abrir un proceso penal, cf. Aznar, "Los 'delicta graviora' reservados", 303 .

72 Se podría generar, por ejemplo, una tendencia a considerar que si los nuevos supuestos del m. p. los realiza un clérigo son siempre delito reservado por ese motivo; y aparte de lo cuestionable que esto sería, habría quien no lo vería así y se daría lugar a una situación eclesial en la que unos casos se enfocan de una manera y otros de otra en estas cuestiones, lo cual no sería nada bueno. Se podría hacer una interpretación más matizada considerando, por ejemplo, que los casos de abuso de autoridad no están reservados a la CDF por su mayor asimilación con los supuestos del c. 1395 §2 que no lo están, pero esto seguiría siendo operar en un entorno de interpretaciones y analogías que chocaría con los cc. 18 y 19 y adolecería de una inseguridad jurídica que se debería evitar. En los que serían nuevos delitos cometidos por un religioso que no es clérigo o una religiosa, cabe entender que en mayor o menor medida se darían los problemas que se han señalado. Se podría suscitar, asimismo, la cuestión de qué tratamiento habría de darse en materia de causas de expulsión del IR del c. 695 §1 a los nuevos supuestos relativos al abuso de autoridad, a la pornografía infantil y a «persona vulnerable». 
también se podría hacer una lectura menos «solemne» (por así decir) de esta cuestión, y plantearse si el m. p. tiene realmente la intención de dar la condición de delito canónico a los supuestos que engloba y no estaban en tipos penales ya existentes al promulgarse. En este sentido podría ser muy significativo que el texto no vuelve a referirse al conjunto de los supuestos que integra empleando el término "delitos», habiendo pasajes en los cuales lo más evidente habría sido hacerlo y en los que emplea en cambio los términos «hechos»o «conductas» (art. 2 §3, 3, 6, $12 \S 1 \mathrm{a}, 12 \S 8,15)^{73}$. Por otra parte, también puede ser relevante observar que el texto habla de presentar informes-información y no de «denunciar», término que tiene una mayor y más clara connotación de referirse a la condición delictiva de aquello que se denuncia. Lo mismo se podría decir, por ejemplo, de «acusar» $\mathrm{o}$ "presentar acusaciones», términos que tampoco aparecen ${ }^{74}$. Cabe añadir que el art. $1 \S 1 \mathrm{~b}$, refiriéndose a las investigaciones que interfieren o eluden las personas del art. 6, habla de «investigaciones... administrativas o penales» sobre casos del art. $1 \S 1 \mathrm{a}$; lo cual invita a pensar que asume la condición no delictiva de al menos algunos de ellos.

${ }^{73} \mathrm{El}$ art. $7 \S 1$ habla de «delitos reservados a la CDF», pero no contradice lo apenas propuesto pues en cualquier hipótesis habrá algunos delitos reservados entre los supuestos del m. p. y a ellos en particular se refiere aquí. Se podría decir que el uso del término «delitos» el en c. $695 \$ 1$ cuando dice «debe ser expulsado el miembro que cometa uno de los delitos de los que se trata en los cc. .... 1395» no fue especialmente afortunado dado que establece una causa de expulsión del IR para cualquiera de sus miembros, pues los delitos del c. 1395 (también los del §1) solo lo son si los comete un clérigo y en los IR hay miembros que no lo son. Quizá hubiera hecho mejor en decir «quien cometa alguno de los hechos de los que trata el c. 1395» (sin calificarlos como delitos), así como VELM se refiere a veces a los supuestos que recoge con el término «hechos».

${ }^{74}$ La versión española del CIC emplea el término «denuncia» u otro de la misma raíz en cánones donde las versiones en otras lenguas emplean denounced, denunziare, denuncia, dénoncé, acusse, denunciado o denunciar (cc. 982, 1390, 1619). Estos términos no aparecen en la versión de VELM en ninguno de esos idiomas (inglés, italiano, francés, portugués), las cuales emplean términos como reports, information, segnalazioni, informazioni, signalements, informations, assinalações e informações allí donde la versión española habla de «informar» y de «informes» (art. 2-4, 8-12). Significativo puede ser también que el art. 5 hable de atender a «quienes afirman haber sido afectados» por casos recogidos en el m. p., pues cuando se trata de un delito lo más común es emplear el término «víctima». Esto encaja con la interpretación de que el propio VELM parta de la base de que no todos esos casos son delito. 


\section{UNA VEZ RECIBIDA LA INFORMACIÓN}

Se podría pensar que si un supuesto contemplado en VELM no es un delito canónico el m. p. carece de sentido para él; pero hay razones para considerar que eso no sería así. A la luz del texto en su conjunto, tiene sentido atribuirle fundamentalmente el propósito de potenciar y hasta garantizar que la Iglesia conozca los casos en que se den hechos o conductas contemplados en el art. 1; cosa que no pierde valor por referirse a algunos que no sean delito, y que no es un objetivo de menor relevancia sino todo lo contrario. Hay que celebrar que se haya dado el paso que emprende el m. p. en el sentido indicado, porque es de suma importancia y de un gran valor para los sinceros esfuerzos de la Iglesia por combatir los casos de abuso sexual, por atender debidamente a las víctimas y por ser transparente; algo que se le reclama desde hace tiempo dentro y fuera de ella.

Obviamente, en el valor de este paso está lo que luego se haga con la información; y por supuesto que siempre hay algo que se debe hacer, sea o no sea delito lo que se viene a conocer. Del art. 2 \$3 se desprende el propósito de VELM de que los destinatarios de la información (una vez está en manos de aquel a quien haya de llegar según las disposiciones del m. p.) «procederán en conformidad con el Derecho de acuerdo con lo previsto en cada caso específico». Como ya se ha hecho notar, esta indicación expresaría que se asume que no todos los supuestos tienen el mismo tratamiento en el derecho; y aunque en caso de entender que todos sean delictivos esto encajaría con que unos estarían reservados a la CDF y otros no, tiene igualmente sentido bajo la perspectiva de que a unos se les dará el tratamiento previsto para los delitos y a otros $\mathrm{no}^{75}$.

75 Por ejemplo, en el caso planteado más arriba de un sacerdote y una persona vulnerable que no tiene habitualmente uso imperfecto de razón, la idea sería que, a falta de especificación sobre los aspectos ya comentados, no se conducirían las cosas hacia un proceso penal sino hacia otras medidas; y no se tendría por qué comunicar el caso a la CDF, como se debe hacer en su debido momento cuando se está ante un delito reservado a la Congregación (art. 16 de las normas de 2010). Esto valdría también, por ejemplo, para cualquier hecho del art. 1 §1 a llevado a cabo por una religiosa o un religioso que no sea clérigo. 


\subsection{Casos Que no implican a PERsonas Del aRT. 6}

El propio m. p. desarrolla en su Título II (art. 6-19) lo que se hará en los supuestos del art. 6, el cual los especifica como "conductas recogidas en el art. 1, cometidas» por cardenales, obispos o legados o, durante munere, por clérigos que están o han estado encargados del gobierno pastoral de una diócesis o «entidad a ella asimilada» o de una Prelatura personal o por moderadores supremos de IR de derecho pontificio. Cabe entender que el texto comporta aplicarles a todos ellos las disposiciones del Título II cuando se trata de lo contemplado tanto en el art. $1 \S 1 \mathrm{a}$ como en el $\S 1 b^{76}$.

Con esto quedaría que para los hechos del art. 1 §1a —que tienen en sí mismos y de manera directa un contenido sexual: realizar actos sexuales, obligar a tenerlos, acciones relacionadas con la pornografía infantil y las exhibiciones pornográficas - llevados a cabo por clérigos y religiosos/as de los que no se trata en el art. 6 (recordemos que lo recogido en el art. $1 \S 1 \mathrm{~b}$ no se refiere a ellos) el m. p. no prevé nada especial, de modo que en estos casos vale sin más la remisión apenas mencionada del art. $2 \S 3$ a que se proceda en cada uno de ellos según lo que el derecho disponga específicamente para él. Diríamos, pues, siguiendo el enfoque ya indicado, que si fuera un delito tipificado antes de VELM se procedería conforme a lo previsto en el derecho para los delitos, lo cual comportaría seguir el cauce de las normas de 2010 para delitos reservados a la CDF cuando se trate de un delito así; y en los demás casos por supuesto que tener información sobre ellos es importante y debe llevar igualmente a emprender acciones y a tomar medidas, aunque no sea la de remitir el asunto a la CDF ni abrir un proceso penal e imponer una pena canónica. Habrá que acceder a la persona perjudicada para atenderla y ayudarla (art. 5) e incluso poder plantear alguna posible reparación por el daño padecido; y con respecto al clérigo o religioso/a, se le podrá confrontar

\footnotetext{
${ }^{76} \mathrm{Al}$ referirse a «conductas» del art. 1, se podría pensar que las disposiciones del Título II solo se aplican a supuestos en los que estas personas del art. 6 (con la indicación durante munere en algunos casos) eluden o interfieren la investigación de casos del art. $1 \S 1 \mathrm{a}$, pues a esos supuestos se refiere el art. 1 en el $\S 1 \mathrm{~b}$ con el término «conductas». Sin embargo, en otros lugares del Título II —art. $12 \S 1 \mathrm{a}, 12$ §8, 15— se habla de «hechos» y se ve que hacen referencia a todo lo recogido en el art. 1; por lo cual cabe entender que lo dispuesto en este Título se refiere también a los supuestos del art. $1 \S 1$ a cuando el autor es persona del art. 6. Sobre otros usos de los términos «hechos» $\mathrm{y}$ «conductas» que podrían resultar algo confusos, ver las notas 33 y 39.
} 
con respecto a lo sucedido, conocer su situación personal para dar respuestas adecuadas e, incluso, tomar medidas de control sobre su vida y conducta que no sean, estrictamente hablando, una pena canónica ${ }^{77}$. Un medio al que se puede acudir es el precepto penal (c. 1319), que sin duda sitúa las cosas de cara al futuro en un ámbito que ya sí es prácticamente penal ${ }^{78}$.

\subsection{CASOS QUE IMPLICAN A PERSONAS DEL ART. 6}

En cuanto a las personas y situaciones del art. 6, el Título II parte —como ya se vio—-de que, según el art. 8 §1, la información llega a manos del metropolitano que corresponde según el domicilio de «la persona señalada ${ }^{79}$. Este solicitará «de inmediato al dicasterio competente el encargo de iniciar la investigación» (art. 10 §1); dicasterio que, en un máximo de 30 días a partir de recibir la solicitud, «procederá sin demora [...] proporcionando las instrucciones oportunas sobre cómo proceder en

77 Incluso habiendo motivos para un proceso penal (cuando hay un delito), el c. 1341 pide que se plantee la adopción de medidas alternativas a las penas que puedan alcanzar los fines de reparación, justicia y enmienda «del reo» que estas buscan. Se entiende que tanto o más sentido tiene acudir a estas alternativas en casos que, aun no siendo el tipo penal de ningún delito, reclaman claramente una respuesta.

${ }_{78}$ Un precepto penal impone obligaciones que, a base de mandatos y prohibiciones, pueden diseñar para la persona a la cual se dirige un determinado régimen de vida sometido a control (no frecuentar determinados lugares y tipos de personas, dar cuenta frecuentemente de sus actividades, estar diariamente a partir de cierta hora en un determinado lugar, etc.). Es característico de este instrumento canónico que en él se establece una pena para la persona en caso de que no cumpla las obligaciones que se le imponen; de modo que, si esto ocurre, se puede proceder como se hace con los delitos y llegar a la imposición de la pena. Sobre el precepto penal, cf., p. e., John A. Renken, The Penal Law of the Roman Catholic Church. Commentary on Canons 1311-1399 and 1717-1731 and Other Sources of Penal Law (Ottawa: Saint Paul University, 2015), 63-66. Si se imponen los mandatos y prohibiciones sin establecer ya una pena para el caso de incumplirlos, estaría la posibilidad de encauzar la desobediencia, si persiste después de una amonestación, como delito del c. 1371.1. Sobre este canon, cf. Carlos. J. Errázuriz, "Comentario al c. 1371", en Comentario exegético..., vol. IV/I, 502-503.

${ }^{79}$ Como se vio más arriba se contemplan también otros supuestos más circunstanciales, de los cuales se prescinde ahora. 
el caso concreto» (art. $10 \S 2)^{80}$. El art. 12 va desglosando el desarrollo de la investigación por el metropolitano, o por «una o más personas idóneas» a las cuales se la encomiende, indicando que procederá una vez recibido el encargo del dicasterio y ateniéndose a las instrucciones que este le dé ${ }^{81}$.

Por lo que se refiere al dicasterio competente el art. $7 \S 1$ dispone que será la CDF si se trata de delitos a ella reservados. Esto encaja con las normas de 2010 sobre dicha materia por cuanto le dan la competencia en todos esos delitos incluso cuando se imputen a un cardenal, obispo

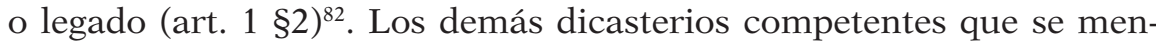
cionan son la Congregación para los Obispos, la Congregación para la Evangelización de los Pueblos, la Congregación para el Clero y la Congregación para los Institutos de Vida Consagrada y Sociedades de Vida Apostólica ${ }^{83}$. Esto está en línea con que el m. p. también abarca casos de delitos no reservados a la CDF, y no choca con el enfoque expresado más arriba de que haya incluso algunos a los cuales no se daría el tratamiento correspondiente a los delitos ${ }^{84}$. La idea de dicho enfoque sería, como

${ }^{80}$ El citado artículo dispone que el metropolitano comunica el informe al legado pontificio si estima que es infundado. El m. p. contempla otras hipótesis más sobre la recepción del informe por el dicasterio competente. Aquí tampoco se entra en ellas por centrar la atención en los supuestos que serán habituales.

${ }^{81} \mathrm{El}$ art. 11 prevé la posibilidad de que el dicasterio competente considere más oportuno encomendar la investigación a una persona distinta del metropolitano, en cuyo caso esta asumiría el papel que se va diseñando para el primero a lo largo del texto.

${ }^{82}$ Para estos delitos las normas de 2010 concretan así en la competencia de la CDF los diversos supuestos que se pueden dar según lo establecido por el c. 1405 cuando dispone, con carácter más general, que son competencia exclusiva del papa los casos que se refieren a los cardenales, a los legados y, sin son penales, a los obispos. Sobre este punto, cf. Aznar, "Los 'delicta graviora' reservados", 305-306.

${ }_{83}$ Menciona también en el art. 7 §1 a la Congregación para las Iglesias Orientales, pero ya se dijo que, por simplificar, prescindiremos aquí de este importante ámbito de la Iglesia católica; lo mismo que en el marco de los IVC y SVA todo se refiere a los IR y tampoco se habla de los monasterios sui iuris.

${ }_{84}$ No serían delito reservado de personas del art. 6, por ejemplo, los del art. $1 \S 1 \mathrm{~b}$, considerando el planteamiento ya expresado de que serían casos del delito no reservado del c. 1389. Sobre supuestos del art. 1 §1a que no habría por qué considerar delitos reservados, se ha ofrecido anteriormente algún ejemplo (empleo de violencia y amenazas por un clérigo) que vale también para personas del art. 6; como valdrían los ejemplos que se dieron de supuestos de ese art. 1 §1 a sobre los cuales se ha planteado que no habría siquiera por qué encauzarlos por el tratamiento previsto para los delitos: acto sexual de un clérigo con abuso de autoridad o con persona vulnerable 
ya se ha planteado, que en los casos que sean delito reservado a la CDF se seguirán las normas sobre esta materia de 2010, en los que fueran delitos no reservados se aplicaría el tratamiento previsto en el CIC para los delitos, y en los que no se siguiera ese cauce se adoptarían medidas oportunas distintas a la apertura de un proceso penal y a la imposición de una pena ${ }^{85}$.

Junto con el art. 12, los art. 13-17 conforman un conjunto de disposiciones relativas a esta investigación prevista en VELM que es mucho más completo que lo dispuesto en el CIC acerca de la que, en el ámbito penal, se denomina «investigación previa» o «preliminar», la cual debe poner en marcha el ordinario que tiene «noticia [...] de un delito» cuando estima que esta es «al menos verosímil» (c. 1717 §1) ${ }^{86}$. Es interesante observar que, mientras para los delitos reservados a la CDF lo previsto en las normas de 2010 es que el ordinario haga la investigación preliminar y la remita al dicasterio cuando la termine, en estos casos que impli-

que no tiene habitualmente uso imperfecto de razón, acciones de un clérigo relacionadas con la pornografía infantil no integradas en el tipo penal tocante a esta materia tipificado como delito en 2010, o hechos cometidos por religiosas o religiosos que no son clérigos (valdría para el supuesto del art. 6 de los superiores/as generales de IR laical de derecho pontificio).

${ }^{85}$ La lista de congregaciones mencionadas junto a la CDF se adecúa a los posibles casos, aparte de los que sean delitos reservados, de personas del art. 6, pues entre ellas hay obispos - los cardenales lo son (ver la nota 18) y sobre los legados ya se mencionó que el art. 8 §3 prevé la intervención de la Secretaría de Estado- hay clérigos y hay religiosos/as (los moderadores supremos que se mencionan). Se entiende que la congregación que sea competente depende de qué condición tenga la persona implicada. La Congregación para la Evangelización tiene competencia exclusiva en algunos territorios, cf. "La Congregación para la Evangelización de los Pueblos", Santa Sede, visitado en septiembre de 2019, http://www.vatican.va/roman_curia/congregations/cevang/documents/rc_con_cevang_20100524_profile_sp.html (n. 4). Ver también los nn. 85-92 de Pastor bonus (ver la nota 41 anterior).

${ }^{86}$ Las mencionadas disposiciones del m. p. hacen referencia, por ejemplo, a las fuentes de información a las que recurrir, al contacto con quien haya sido perjudicado por el caso en cuestión y con la persona investigada, a la posibilidad de defenderse de esta última y a la presunción de su inocencia, a la custodia segura de lo que se vaya recabando, a los posibles conflictos de intereses que puedan afectar la imparcialidad del metropolitano, a su regular información al dicasterio competente (mensualmente) sobre la marcha de la investigación, a que él mantiene siempre la responsabilidad sobre la misma aunque la lleven a cabo otras personas, al tiempo en el cual debería estar terminada (en principio 90 días) y a contar con una lista de personas idóneas que pudieran colaborar en ella y con un fondo para afrontar los gastos que comporte. 
can a personas del art. 6, es el dicasterio competente (incluida la CDF) el que encarga investigar habiendo recibido antes el informe-información. Cabe entender que, ante la mayor relevancia eclesial de las personas implicadas, se ha visto mejor anticipar la intervención de la Santa Sede, lo cual resulta muy razonable. Pensemos en lo desproporcionado de una situación en la que un «simple» ordinario (por así decir) tuviera noticia de un hecho que debe investigar e implique, por ejemplo, a un cardenal $^{87}$. Quizá se podría pensar en llevar en alguna medida el modo de afrontar las cosas en el m. p. a más supuestos de los contemplados en él (por ejemplo, a los demás delitos reservados a la CDF), adaptando según los niveles y casos $^{88}$.

Otra normativa con la que habría que cotejar VELM sería el también m. p. del papa Francisco Como una madre amorosa, de 4 de junio de $2016^{89}$. Este documento se refiere (art. 1) a casos de obispos diocesanos o equiparados a ellos por el c. 381 (se habló de esto más arriba) y de superiores mayores de IR y SVA de derecho pontificio que han causado un daño grave físico, moral, espiritual o patrimonial a personas o a la comunidad, por negligencia muy grave al poner $\mathrm{u}$ omitir actos en su gobierno pastoral, o simplemente grave si se trata de la gestión de casos de abuso a menores de edad o adultos vulnerables. Este m. p. también prevé (art. 2) una investigación del caso a cargo de una congregación competente (no especifica más), la posibilidad de defensa y que el dicasterio (art. 3) pueda tomar la decisión de remover al obispo o al cargo de que se trate (art. 4). Como se ve, seguramente hay supuestos que se solapan

$87 \mathrm{Si}$ acaso se podría decir que, cuando se tratare de un supuesto del art. 6 referido a quien fue moderador supremo de un IR de derecho pontificio, quizá tendría sentido que la investigación se pusiera bajo la responsabilidad del actual superior general; y si fuera él el implicado, bajo la del superior general de otro IR. Bien es verdad que en el primer supuesto se darían fácilmente conflictos de intereses que afecten a la imparcialidad y que serían mucho menos probables estando la investigación bajo la responsabilidad del metropolitano; y en todo caso, las posibilidades mencionadas podrían verificarse si el dicasterio competente lo estima oportuno, pues ya se ha dicho que el m. p. prevé que pueda encomendar la investigación a otra persona (ver la nota 81).

88 Se podría pensar también, por ejemplo, en que los oficios-oficinas del art. 2 §1 sirvan para presentar denuncias por cualquier delito canónico y no solo para informes sobre supuestos de VELM, sin perjuicio de tener una sección más dedicada a ellos.

$89 \mathrm{Cf}$. http://w2.vatican.va/content/francesco/it/motu_proprio/documents/papa-francesco-motu-proprio_20160604_come-una-madre-amorevole.html. Para una versión española, cf. https://es.zenit.org/articles/carta-apostolica-del-santo-padre-francisco-como-una-madre-amorosa-texto-completo/ 
con los del art. 1 §1b VELM, y convendría estudiar el deslinde entre los abarcados en un m. p. y otro para ver el cauce que haya de darse a cada caso. Como quiera que sea, es interesante observar que Como una madre amorosa elude en gran medida la terminología penal; especialmente en la medida prevista, pues habla de «remoción» cuando la pena canónica se denomina "privación» (cc. 196 y 1336 §1.2), y aun cuando ambas comportan la pérdida de un oficio, siempre estará la diferencia de que la segunda comporta haber cometido un delito y la primera $\mathrm{no}^{90}$.

En este sentido, se podría decir que el m. p. de 2016 marca, en alguna medida, un camino que se sigue en VELM, pues en realidad también el Título II parece ladear la terminología penal ${ }^{91}$; lo cual podría avalar la idea de que no pretende que todos los supuestos abarcados sean delito ${ }^{92}$. De hecho, en cuanto se refiere a las «medidas posteriores» a la investigación y la defensa de la persona implicada, el art. 18 vuelve a remitirse sin más a que en cada caso se "procede en conformidad con el derecho de acuerdo con lo previsto en cada caso específico».

\section{ORIGEN DE LA INFORMACIÓN Y LEYES ESTATALES}

Se entiende que quien aporta información sobre algún caso contemplado en VELM puede adquirirla de diversas maneras, como podría ser por haber presenciado unos hechos, por haberlos puesto en su conocimiento quien los ha padecido $\mathrm{u}$ otra persona, por haber solicitado una medida que no se llevó a cabo, por haberse visto afectado en otra que sí se puso en marcha, etc. Sobre esto hay dos disposiciones interesantes en el m. p.

Una sería el art. $3 \S 1$, según el cual la obligación de informar que se impone a los clérigos y religiosos cede, y no se habrá de cumplir, en los casos del c. 1548 §2. Este canon viene a comportar, por remisión al c.

90 En realidad, Como una madre amorosa presenta dificultades de encaje con el delito ya mencionado del c. 1389, no quedando claro los casos de este canon que deja fuera y aún tendrían su cauce en la vía penal. Sobre esta cuestión, cf. José Luis Sánchez-Girón, "El motu proprio Como una madre amorosa a la luz de la normativa codicial”, Estudios Eclesiásticos 91 (2016): 843-860.

91 Ya se ha mencionado que salvo en la introducción y el art. 1 no habla de «delitos», y que no habla de «víctima» ni de «denuncias».

92 Ver la nota 84. 
1550 \$2.2, que un sacerdote no puede revelar nunca y bajo ninguna circunstancia lo que conozca porque se lo aporta alguien que se ha confesado con él en el sacramento de la penitencia o de la reconciliación (se corresponde con el c. 983, que prohíbe al confesor violar el llamado «sigilo sacramental», estando su violación tipificada como delito en el c. 1388$)^{93}$. Esto aparte, el c. $1548 \S 2$ se refiere a los ministros sagrados (los clérigos, según el c. 207§1), los magistrados civiles, médicos, comadronas, abogados y notarios, indicando que están obligados a guardar «secreto de oficio» sobre lo que se les haya confiado en tanto que tales (al médico por ser médico y en el marco de su labor, al clérigo por ser ministro sagrado, etc.) y asumiendo que esto se da en más casos que los cinco mencionados; pensemos, por ejemplo, en los psiquiatras y psicólogos o en los mediadores familiares y en otros casos así. Se diría que ninguno de ellos debe atender a la obligación de informar del art. 3 §1 en lo que sean confidencias recibidas por razón del oficio (entiéndase del ministerio en el caso de los clérigos); lo cual habrá que confrontar con el art. 4 §1 según el cual «El hecho de presentar un informe en conformidad con el artículo 3 no constituye una violación del secreto de oficio", lo que puede ponerse en relación con el hecho de que, excepto en el caso del sigilo sacramental, es posible dispensar de la obligación de guardar el secreto de oficio ${ }^{94}$.

93 Sobre esta cuestión se ha pronunciado la Santa Sede el 29 de junio de 2019 mediante la "Nota de la Penitenciaría Apostólica sobre la importancia del fuero interno y la inviolabilidad del sigilo sacramental” -cf. http://www.vatican.va/roman_curia/tribunals/ apost_penit/documents/rc_trib_appen_pro_20190629_forointerno_sp.html (consultado en septiembre de 2019) - acompañada de nota de presentación, cf. http:/www.vatican. va/roman_curia/tribunals/apost_penit/documents/rc_trib_appen_pro_20190629_forointerno-cardpiacenza_it.html (consultado en septiembre de 2019).

${ }_{94}$ Cf. Manuel Jesús Arroba Conde, "Comentario al c. 1548”, en Código de derecho Canónico. Edición bilingüe, fuentes y comentario de todos los cánones, dir. Antonio Benlloch Poveda, 9. ${ }^{a}$ ed. (Valencia: EDICEP, 2001), 677-678. Un espacio muy propio del ministerio sacerdotal en el que se dan confidencias a las que afectaría este secreto de oficio y que no es el sacramento de la confesión (no estaría sujeto al inviolable y no dispensable sigilo sacramental) sería lo que se conoce como dirección o acompañamiento espiritual. También entraría en esta problemática lo que se conoce, especialmente en la vida religiosa, como cuenta de conciencia al superior, que tiene una especial significación en algunos IR; concretamente en la Compañía de Jesús. Sobre esta cuestión cf. José Luis Sánchez-Girón "La cuenta de conciencia al Superior: relación entre carisma y derecho”, Periodica 102 (2013): 211-240. 
La conciliación entre ambas disposiciones puede no ser fácil. Podría estar en que las personas mencionadas, en cuanto se trate de información relativa a los supuestos de VELM y en las condiciones previstas por el m. p., pueden aportar la que conozcan en razón del ministerio u oficio porque están dispensadas por el art. 4 §1 de la obligación de no hacerlo que impone el secreto de oficio; pero puede que aún no quede claro si con respecto a esa información así adquirida la dispensa conlleva que están sujetos a la obligación de informar del art. 3 §1 o si están autorizados a informar pero no obligados ${ }^{95}$.

Como quiera que sea, la Iglesia puede conducir las cosas de una u otra manera en lo que toca a su propio ámbito, a su propio derecho; pero los fieles (clérigos incluidos, como es evidente) son también ciudadanos de sus respectivos Estados, y están sujetos a sus ordenamientos jurídicos. Por tanto, no se debe pasar por alto lo que en ellos se disponga, máxime cuando el art. 19 del m. p. establece que este se aplique sin perjuicio de atender a lo que en ellos se contemple. Hay ordenamientos estatales que imponen la obligación de guardar el secreto de oficio en diversas profesiones y funciones, incluidas las de los ministros de las religiones entre los cuales están los clérigos de la Iglesia católica; y faltar a esa obligación podría suponer serias sanciones. No obstante, es verdad que hay una creciente tendencia a sacar de esta obligación la información relativa a abusos sexuales, especialmente si son de menores que, en general, están considerados como delito en los ordenamientos estatales. Habría que estudiar en cada caso en qué medida el cumplimiento de la ley canónica puede chocar con la del Estado ${ }^{96}$.

${ }_{95}$ Habría que ver si dispensar de una obligación puede o no comportar que se quede necesariamente sujeto a otra. Obviamente, la información obtenida por cauces que no comportan secreto de oficio está sujeta sin más a la obligación del art. $3 \S 1$. También podría relacionarse con estas cuestiones el art. $3 \S 5$, en cuanto dispone que "las noticias también pueden obtenerse ex officio». La norma podría hacer referencia, en coherencia con el art. $4 \S 1$, a que se admite información sobre supuestos del m. p. recabada en el ejercicio de oficios y ministerios donde hay secreto de oficio; y no se limitaría a esto, sino que podría abarcar la que se adquiera en el ejercicio de cualquier otro oficio, así como la iniciativa proactiva de los oficios-oficinas del art. 2 §1 de cara a fomentar entre la gente que se informe.

96 En el caso de España habría que atender al menos al art. 13 de la Ley del Menor de 2015, así como a los art. 262, 263 y 417 de la Ley de Enjuiciamiento Criminal, al art. 191 del Código Penal y al art. II.3 del Acuerdo con la Santa Sede de julio de 1976 (B.O.E. de 24/09/1976). 
Hay casos en los cuales la ley estatal obliga a los sacerdotes a poner a disposición de las autoridades información relativa a abusos sexuales obtenida en el sacramento de la confesión, entrando en fuerte conflicto con el sigilo sacramental ${ }^{97}$. Por otro lado, hay que atender también a lo que dispongan los ordenamientos jurídicos en cuanto a que las autoridades de la Iglesia colaboren con las del Estado (más allá de informar) cuando estas están actuando en un caso, e incluso a poner a su disposición la documentación que tengan acerca del mismo ${ }^{98}$.

\section{CONCLUSIONES}

Antes que ninguna otra cosa VELM merece una valoración positiva por haber potenciado notablemente algo tan relevante como es que la Iglesia tenga conocimiento de los casos de abuso sexual cometidos por clérigos y religiosos. Es importante que un diseño de los procedimientos como el de este m. p. (siempre susceptible de perfilarse más en lo concreto en unos lugares y otros) esté en un documento de valor jurídicamente vinculante, pues hasta ahora no era suficiente con lo que había en esta materia en los documentos de ese nivel, si bien se han podido hacer avances con el impulso y la motivación generada por textos más

97 Cf. "Secreto de confesión y abusos sexuales", Rafael Navarro-Valls, visitado en septiembre de 2019, https:/www.elmundo.es/opinion/2018/09/06/5b8fb547268e3e003c8b45b6.html. El autor hace notar que en Canberra (Australia) la ley obliga a los sacerdotes a informar sobre abusos sexuales de los que tengan noticia por la confesión sacramental. También, cf. Thaddeus Mbadiwe Osuala, "The Sacramental Seal According to Canon $983 \S 1$ in light of Mandatory Child Abuse Reporting Legislations" (Tesis doctoral en Derecho Canónico, UPSA-Salamanca, 2019); "Sigilo sacramental y denuncia obligatoria de abuso de menores. Una mirada global", REDC 76 (2019): 215-239.

98 Cf. Jesús Rodríguez Torrente, "Proceso penal canónico y colaboración con la justicia estatal en los delitos de abusos sexuales", en Reforma de los procesos de nulidad y otras novedades legislativas de Derecho Canónico y Eclesiástico del Estado, Actas de las XXXVI Jornadas de Actualidad Canónica, dir. Lourdes Ruano, Cristina Guzmán (Madrid: Dykinson, 2017), 57-60.63-65. Aquí también habría que tener en cuenta los planteamientos recientemente expresados por la Penitenciaría Apostólica (ver la nota 93), en la idea tomar en consideración la naturaleza y las características que adquieren en la Iglesia a las relaciones de confidencialidad a la hora de abordar la colaboración con las actuaciones de las autoridades estatales cuando se trata de información recabada por las eclesiales en el ámbito del llamado «fuero interno». 
indicativos y orientadores de lo que se puede e incluso se invita a hacer. El paso que se ha dado estaría llamado a generar más frutos tangibles y una mejor percepción del compromiso de la Iglesia en afrontar este tipo de casos y prevenir que no los haya.

La complejidad de la estructura de la Iglesia (diversidad de cargos, instituciones, circunscripciones, etc.) hace realmente complicado trazar el diseño de un modo de proceder que valga para toda ella en su implantación universal, y seguramente algunos puntos del m. p. pueden no quedar del todo claros (en particular, por el uso de ciertos términos en unos lugares y otros); pero quizá esto sea en parte inevitable y, en cualquier caso, tampoco se debe pretender que sea fácilmente accesible a cualquiera. No ha de faltar quien pueda resolver dudas y oscuridades, y no sería justo quitar valor al esfuerzo de la Iglesia porque estas se perciban.

En cuanto a lo dispuesto en el m. p. acerca de lo que ha de hacerse con la información recogida, cabe destacar que haya un tratamiento especial para los casos en que están implicadas personas de especial relevancia y significación en la Iglesia, como son las que aparecen en el art. 6. Algunos supuestos que se refieren a ellas muestran que la Iglesia también quiere entrar en un espacio decisivo para el propósito de una adecuada gestión del grave problema de los abusos, como es el ejercicio de las responsabilidades de gobierno. Así las previsiones relativas a la información se refieren también a los casos de mal gobierno que, por acción u omisión, dañan ese propósito.

Dicho sea con humildad y modestia, y siempre a salvo de mejor criterio, se podría decir que en VELM también quedan algunas cosas importantes por perfilar. Concretamente, si se consolida lo que, al denominar «delitos» a todo un conjunto de supuestos, pudiera entenderse como el propósito de tipificar penalmente todos los que no tenían la condición de delito en la Iglesia antes del m. p. Aquí se ha hecho notar esta cuestión, y se ha planteado que para consolidar ese propósito habría que establecer la pena para estos supuestos y, aunque en otro nivel de necesidad, precisar si algunos serían delitos reservados a la CDF y en tal caso cuáles. Según el enfoque aquí planteado, mientras esto no se clarifique no se podría dar a estos nuevos supuestos un adecuado tratamiento penal y sería mejor no enfocarlos por esa vía. Por otra parte, habría elementos en el m. p. que invitan a pensar que él mismo asume la condición no delictiva de algunos supuestos, y en esta línea de interpretación las especificaciones anteriores podrían darse o no en todos 
los casos. Ciertamente, en los últimos tiempos los supuestos contemplados son, en general, delictivos en los ordenamientos estatales, pero no hay que dejar de considerar que el hecho de que algo sea delito en la ley del Estado puede ser compatible con no serlo en la canónica, como pasa en sentido inverso.

Posiblemente convendría aclarar mejor lo que se refiere a la obligación de informar cuando se trata de información adquirida en el marco confidencial del secreto de oficio, pues pueden surgir dudas que sin embargo no tienen cabida con respecto al sigilo sacramental, ya que en el m. p. se mantiene su condición inviolable. También habrá que mirar en cada país el encaje entre lo previsto en VELM y la legislación estatal, tomando las posiciones más conciliadoras posibles sin dejar de mantener elementos irrenunciables de Iglesia como el propio sigilo sacramental.

Nada de esto quita para decir, ante todo, que estamos ante un documento muy valioso. Hay motivos para celebrar el paso que con él se ha dado y esperar que, con apoyo de todos y la ayuda del Señor, la Iglesia vaya adelante en su voluntad de gestionar bien el problema de los abusos sexuales, tomando medidas adecuadas de un tipo u otro contra quienes los cometan, atendiendo a quienes los hayan padecido, generando normas bien construidas cuya aplicación produzca frutos de justicia para todos y mejorando los espacios que en ellas queden oscuros o necesiten de una normativa específica.

\section{REFERENCIAS}

Alwan, Hanna G. “Acción criminal”. En Diccionario General de Derecho Canónico, dirigido por Javier Otaduy, Antonio Viana, y Joaquín Sedano, vol. I, 112-116. Cizur Menor, Navarra: Universidad de Navarra-Thomson Reuters Aranzadi, 2012.

Arrieta, Juan Ignacio. "Prelatura personal". En Diccionario General de Derecho Canónico, dirigido por Javier Otaduy, Antonio Viana, y Joaquín Sedano, vol. VI, 389-399. Cizur Menor, Navarra: Universidad de Navarra-Thomson Reuters Aranzadi, 2012.

Arroba Conde, Manuel J. "Comentario al c. 1548”. En Código de derecho Canónico. Edición bilingüe, fuentes y comentario de todos los cánones, dirigido por Antonio Benlloch Poveda, 677-678. 9. a ed. Valencia: EDICEP, 2001. 
Astigueta, Damián. "La persona e i suoi diritti nelle norme sugli abusi sessuali". Periodica 93 (2004): 623-691.

Aznar Gil, Federico R. "Los 'delicta graviora' reservados a la Congregación para la Doctrina de la Fe: Texto modificado (2019)". Revista Española de Derecho Canónico 68 (2011): 283-313.

Bernal, José. “Delicta graviora”. Ius canonicum 58 (2018): 357-368.

Boutros, Naaman. "Aspetti giuridico-teologici delle sanzioni e delle pene canoniche alla luce dell'Ecclesiologia di comunione del Concilio Ecumenico Vaticano II". Tesis doctoral en Derecho Canónico. P. U. Lateranense, 2002.

Cafardi, P. "Stones Instead of Bread: Sexually Abusive Priests in Ministry”. Studia Canonica 27 (1993): 145-172.

Calabrese, Antonio. Diritto penale canonico. 2. ${ }^{a}$ ed. Città del Vaticano: Librería Editrice Vaticana, 1996.

Cardia, Carlo. "Cardenal". En Diccionario General de Derecho Canónico, dirigido por Javier Otaduy, Antonio Viana, y Joaquín Sedano, vol. I, 852-855. Cizur Menor, Navarra: Universidad de Navarra-Thomson Reuters Aranzadi, 2012.

Errázuriz, Carlos J. “Comentario al c. 1371”. En Comentario exegético al Código de Derecho Canónico, dirigido por Ángel Marzoa, Jorge Miras, y Rafael Rodríguez-Ocaña, vol. IV/1, 499-503. 3. a ed. Barañáin-Navarra: EUNSA, 2002.

Felipe Freije, Rafael. "Respuesta eclesial y canónica a los abusos sexuales de menores bajo el impulso de J. Ratzinger, Prefecto y Papa". Tesis doctoral en Derecho Canónico, U. P. Comillas-Madrid, 2019.

Ghirlanda, Gianfranco. El derecho en la Iglesia misterio de comunión. Compendio de derecho eclesial. Madrid: Ediciones Paulinas, 1992.

Gómez Martín, E. "El delito contra el sexto mandamiento del Decálogo cometido por un religioso con un menor". Revista Española de Derecho Canónico 69 (2012): 166-224.

Haering, Stephan. "Instituto de derecho pontificio". En Diccionario General de Derecho Canónico, dirigido por Javier Otaduy, Antonio Viana, y Joaquín Sedano, vol. IV, 641-644. Cizur Menor, Navarra: Universidad de Navarra-Thomson Reuters Aranzadi, 2012.

Horta, Jorge. "Superior General". En Diccionario General de Derecho Canónico, dirigido por Javier Otaduy, Antonio Viana, y Joaquín Sedano, vol. VII, 457-460. Cizur Menor, Navarra: Universidad de Navarra-Thomson Reuters Aranzadi, 2012. 
Kimes, John P. "Simul et cura et solertia. Guidelines of the Episcopal Conferences for dealing with cases of sexual abuses of minors perpetrated by clerics". En I delitti riservati alla Congregazione per la Dottrina della Fede. Norme, prassi, obbiezioni, diririgido por Claudio Papale, 45-74. Città del Vaticano: Urbaniana University Press, 2015.

Kuminetz, Geza. "Monasterio". En Diccionario General de Derecho Canónico, dirigido por Javier Otaduy, Antonio Viana, y Joaquín Sedano, vol. V, 458-460. Cizur Menor, Navarra: Universidad de Navarra-Thomson Reuters Aranzadi, 2012.

Malvaux, Benoit. "Instituto de derecho diocesano". En Diccionario General de Derecho Canónico, dirigido por Javier Otaduy, Antonio Viana, y Joaquín Sedano, vol. IV, 638-640. Cizur Menor, Navarra: Universidad de Navarra-Thomson Reuters Aranzadi, 2012.

Marzoa, Ángel. "Delito". En Diccionario General de Derecho Canónico, dirigido por Javier Otaduy, Antonio Viana, y Joaquín Sedano, vol. II, 1026-1029. Cizur Menor, Navarra: Universidad de Navarra-Thomson Reuters Aranzadi, 2012.

-. "Comentario al c. 1389". En Comentario exegético al Código de Derecho Canónico, dirigido por Angel Marzoa, Jorge Miras, y Rafael Rodríguez-Ocaña, vol. IV/1, 561-563. 3. ${ }^{a}$ ed. Barañáin-Navarra: EUNSA, 2002.

Medina, Ricardo D. "Algunas consideraciones acerca de las modificaciones a las normas de los delitos más graves". Anuario Argentino de Derecho Canónico 16 (2009-2010): 212-160.

Miragoli, E. "La 'pena giusta' nei casi di delicta graviora”. Quaderni di diritto ecclesiale 25 (2012): 356-368.

Miras, Jorge. "Procedimiento administrativo penal". En Diccionario General de Derecho Canónico, dirigido por Javier Otaduy, Antonio Viana, y Joaquín Sedano, vol. VI, 496-498. Cizur Menor, Navarra: Universidad de Navarra-Thomson Reuters Aranzadi, 2012.

Mosconi, Marino. "L'indagine previa el'aplicazione della pena in via amministrativa". En I giudizi nella Chiesa. Processi e procedure speciali, dirigido por Gruppo Italiano Docenti di Diritto Canonico - Associazione Canonistica Italiana, 191-228. Milano: Glossa, 1999.

Otaduy, Javier. "Comentario al c. 18". En Comentario exegético al Código de Derecho Canónico, dirigido por Ángel Marzoa, Jorge Miras, y Rafael Rodríguez-Ocaña, vol. I, 372-379. 3. ${ }^{a}$ ed. Barañáin-Navarra: EUNSA, 2002. 
Paolis, Velasio de. "Norme de gravioribus delictis riservati alla Congregazione per la Dottrina della Fede". Periodica 91 (2002): 273-312.

Paolis, Velasio de, y Davide Cito. Sanzioni nella Chiesa. Commento al Codice di Diritto Canonico Libro VI. 2. ${ }^{a}$ ed. Città del Vaticano: Urbaniana University Press, 2001.

Papale, Claudio. Il processo penale canonico. Commento al Codice di Diritto Canonico. Libro VI, Parte IV. Città del Vaticao: Urbaniana University Press, 2007.

-. "Latae sententiae". En Diccionario General de Derecho Canónico, dirigido por Javier Otaduy, Antonio Viana, y Joaquín Sedano, vol. IV, 975-977. Cizur Menor, Navarra: Universidad de Navarra-Thomson Reuters Aranzadi, 2012.

-. "I delitti contro la morale". En I delitti riservati alla Congregazione per la Dottrina della Fede, dirigido por Andrea D'Auria, y Claudio Papale, 29-46. Roma: Urbaniana University Press, 2014.

Pighin, Bruno F. Diritto penale canonico. Venezia: Marcianum Press, 2008.

Pons Portella, M. "Los supuestos de aplicación extrajudicial de penas en el Derecho Canónico". Ius Canonicum 58 (2018): 212-148.

Renken, John A. The Penal Law of the Roman Catholic Church. Commentary on Canons 1311-1399 and 1717-1731 and Other Sources of Penal Law. Ottawa: Saint Paul University, 2015.

Rincón Pérez, Tomás. "Titulus III. De ministris sacris seu clericis. Introducción”. En Comentario exegético al Código de Derecho Canónico, dirigido por Angel Marzoa, Jorge Miras, y Rafael Rodríguez-Ocaña, vol. II/1, 206-212. 3. . ed. Barañáin-Navarra: EUNSA, 2002.

Rodríguez Torrente, Jesús. "Proceso penal canónico y colaboración con la justicia estatal en los delitos de abusos sexuales". En Reforma de los procesos de nulidad y otras novedades legislativas de Derecho Canónico y Eclesiástico del Estado, Actas de las XXXVI Jornadas de Actualidad Canónica, dirigido por Lourdes Ruano, y Cristina Guzmán, 23-66. Madrid: Dykinson, 2017.

Sánchez-Girón, José Luis. "Delitos contemplados en las normas de gravioribus delictis del año 2010”. Estudios Eclesiásticos 85 (2010): 731-767.

- . "Normas procesales en la regulación de gravioribus delictis del año 2010". Estudios Eclesiásticos 86 (2011): 717-747.

- . "La cuenta de conciencia al Superior: relación entre carisma y derecho". Periodica 102 (2013): 447-482. 
— . "La expulsión de un instituto religioso en los cánones 694-700 a la luz de la normativa del CIC en materia penal". Estudios Eclesiásticos 88 (2013): 699-729.

- . "El motu proprio Como una madre amorosa a la luz de la normativa codicial". Estudios Eclesiásticos 91 (2016): 843-860.

Steinfels, P. A people adrift. New York-London: Simon and Schuster, 2003.

Taylor, Max, y Ethel Quayle. Child Pornography. An Internet Crime. New York: Brunner-Routledge, 2003.

Varnier, Giovanni Battista. "Legado Pontificio". En Diccionario General de Derecho Canónico, dirigido por Javier Otaduy, Antonio Viana, y Joaquín Sedano, vol. IV, 1000-1002. Cizur Menor, Navarra: Universidad de Navarra-Thomson Reuters Aranzadi, 2012.

Veroli, Massimo di. "Pedopornografia: Aspetti tecnico informatici utili all'accertamento delle responsabilità penali da parte dell'autore". En I delitti riservati alla Congregazione per la Dottrina della Fede. Norme, prassi, obbiezioni, dirigido por Claudio Papale, 131-159. Città del Vaticano: Urbaniana University Press, 2015.

Woestman, William H. Ecclesiastical Sanctions and the Penal Process. Otawa: Saint Paul University, 2003.

- . "Instituto clerical". En Diccionario General de Derecho Canónico, dirigido por Javier Otaduy, Antonio Viana, y Joaquín Sedano, vol. IV, 636-638. Cizur Menor, Navarra: Universidad de Navarra-Thomson Reuters Aranzadi, 2012. 